San Jose State University

SJSU ScholarWorks

Master's Theses

Master's Theses and Graduate Research

1996

\title{
Emotional profiles of juvenile offenders with and without post- traumatic stress disorder
}

Nancy J. Schrack

San Jose State University

Follow this and additional works at: https://scholarworks.sjsu.edu/etd_theses

\section{Recommended Citation}

Schrack, Nancy J., "Emotional profiles of juvenile offenders with and without post-traumatic stress disorder" (1996). Master's Theses. 1401.

DOI: https://doi.org/10.31979/etd.st38-q26v

https://scholarworks.sjsu.edu/etd_theses/1401

This Thesis is brought to you for free and open access by the Master's Theses and Graduate Research at SJSU ScholarWorks. It has been accepted for inclusion in Master's Theses by an authorized administrator of SJSU ScholarWorks. For more information, please contact scholarworks@sjsu.edu. 


\section{INFORMATION TO USERS}

This manuscript has been reproduced from the microfilm master. UMI films the text directly from the original or copy submitted. Thus, some thesis and dissertation copies are in typewriter face, while others may be from any type of computer printer.

The quality of this reproduction is dependent upon the quality of the copy submitted. Broken or indistinct print, colored or poor quality illustrations and photographs, print bleedthrough, substandard margins, and improper alignment can adversely affect reproduction.

In the unlikely event that the author did not send UMI a complete manuscript and there are missing pages, these will be noted. Also, if unauthorized copyright material had to be removed, a note will indicate the deletion.

Oversize materials (e.g., maps, drawings, charts) are reproduced by sectioning the original, beginning at the upper left-hand corner and continuing from left to right in equal sections with small overlaps. Each original is also photographed in one exposure and is included in reduced form at the back of the book.

Photographs included in the original manuscript have been reproduced xerographically in this copy. Higher quality 6 " $\times 9$ " black and white photographic prints are available for any photographs or illustrations appearing in this copy for an additional charge. Contact UMI directly to order.

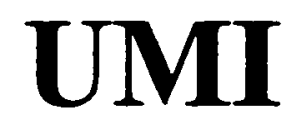

A Bell \& Howell Information Company 300 North Zeeb Road, Ann Arbor MI 48106-1346 USA 


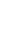




\title{
EMOTIONAL PROFILES OF JUVENILE OFFENDERS
}

\section{WITH AND WITHOUT POST-TRAUMATIC STRESS DISORDER}

\author{
A Thesis \\ Presented to \\ The Faculty of the Department of Psychology \\ San Jose State University \\ In Partial Fulfillment \\ of the Requirements for the Degree \\ Master of Arts \\ by
}

Nancy J. Schrack

December 1996 
UMI Number: 1382605

Copyright 1996 by

Schrack, Nancy Jean

All rights reserved.

UMI Microform 1382605

Copyright 1997, by UMI Company. All rights reserved.

This microform edition is protected against unauthorized copying under Title 17, United States Code.

\section{UMI \\ 300 North Zeeb Road \\ Ann Arbor, MI 48103}


APPROVED FOR THE DEPARTMENT OF PSYCHOLOGY

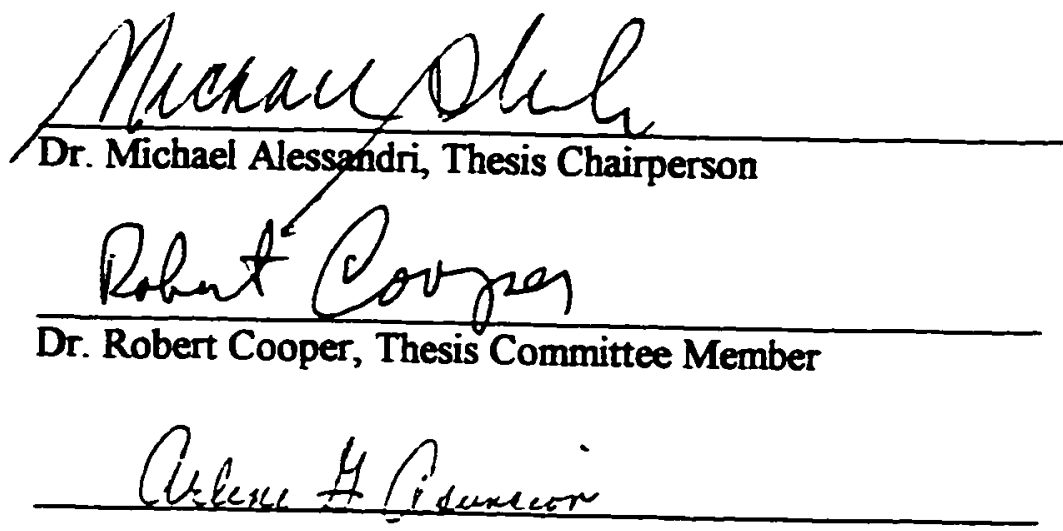

Dr. Arlene Asuncion, Thesis Committee Member

APPROVED FOR THE UNIVERSITY

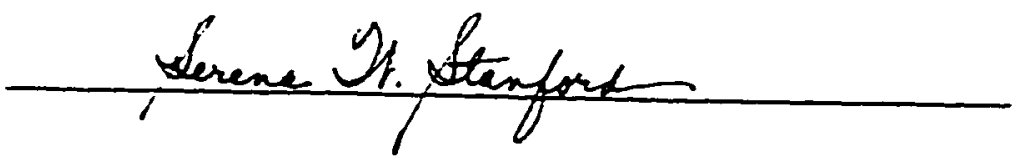


○) 1996

Nancy J. Schrack

ALL RIGHTS RESERVED 


\section{ABSTRACT \\ EMOTIONAL PROFILES OF JUVENILE OFFENDERS \\ WITH AND WITHOUT POST-TRAUMATIC STRESS DISORDER \\ by Nancy J. Schrack}

Using the Children's PTSD Inventory (CPTSD-I; Saigh, 1994), and Emotions

Profile Index (EPI; Plutchik \& Kellerman, 1974) the study examined the frequency of post-traumatic stress disorder (PTSD), the level of aggression, and personality dimensions among juvenile offenders (JO). Ninety-seven JOs from Santa Clara County Juvenile Detention Center in California participated.

Results indicated $57 \%$ of the JOs met the criteria for DSM-IV lifetime diagnosis of PTSD. Furthermore, a $2 \times 2$ MANOVA showed significant differences in aggression levels across groups. Specifically, significantly higher levels of aggression, both active and passive, were found among JOs with PTSD than those without PTSD. Also, an exploratory $9 \times 2$ MANOVA was run on the 9 EPI dimensions (i.e., 8 basic EPI traits and a bias score) by PTSD subgroup. While the overall MANOVA did not reach significance, significant univariate Fs emerged on 4 of the basic E P I dimensions (i.e., Trustful, Gregarious, Aggressive, \& Distrustful) and the Bias score. 


\section{ACKNOWLEDGMENTS}

I would like to express my appreciation and sincere thanks to Dr. Michael

Alessandri for his valuable assistance and time, and for his support for my project. I would also like to thank Dr. Arlene Asuncion for sharing her knowledge and for her helpful suggestions.

My gratitude is also extend to Dr. Cooper, Dr. Feist, Dr. Howard Tokunaga, and to Shirley Cantu (Superintendent of Santa Clara Juvenile Detention Center) and Liz Alameda (Supervisor-Santa Clara Juvenile Detention Center) for their advice and support and to Naomi Jabrack-McDaniel who helped to interview the Juvenile Offenders.

A special thank you to Brian and Sharon Ziel for their encouragement, especially to Sharon for her unfailing editing and help in compiling of this thesis. 
TABLE OF CONTENTS

SECTION

PAGE

INTRODUCTION

l

HYPOTHESES

METHOD

Participants.

Measures.

Procedures.

RESULTS

Design and Analysis

Hypothesis 1

Hypothesis 2

Hypothesis 3 16

Analyses of Demographic Variables. 19

DISCUSSION

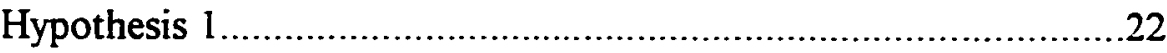

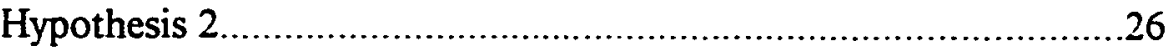

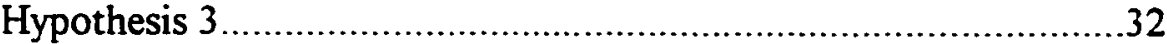

vi 


\section{TABLE OF CONTENTS}

SECTION

PAGE

Additional Findings and Summary Results. 43

REFERENCES 48

APPENDICES .54

Appendix A. Background on Life Events Questionnaire. .55

Appendix B. Children's PTSD Inventory DSM-IV Version. 56

Appendix C. Emotions Profile Index. 70

Appendix D. Oral Instructions. 77

Appendix E. Letter to Potential Participants. 79

Appendix F. Court Informed Consent Form 80

Appendix G. Child Informed Consent Form 81

Appendix H. SJSU Consent Letter to Use Human Subjects. 82

Appendix I Court Consent to Interview Youth. 83

Appendix J. Dr. Saigh Consent to use CPTSD-I 84 


\section{LIST OF TABLES}

TABLE

PAGE

1. Summary of Life Experiences of Juvenile Offenders

2. Emotions Profile Index MANOVA Results

3. Emotions Profile Index Chi-square Results

4. Frequency of PTSD by Ethnicity

5. Aggression Levels in 1994 versus 1996

6. Personality Traits of Juvenile Offenders with PTSD 


\section{LIST OF FIGURES}

FIGURE $\quad$ PAGE

1. Mean Scores on Emotions Profile Index for Juvenile Offenders

With and Without PTSD Line Graph 


\section{EMOTIONAL PROFILES OF JUVENILE OFFENDERS \\ WITH AND WITHOUT POST-TRAUMATIC STRESS DISORDER}

Nancy Jean Schrack

San Jose State University

Running head: EMOTIONAL PROFLLS OF PTSD

Requests for reprints should be sent to Nancy J. Schrack, Department of Psychology,

San Jose State University, San Jose, California 95192. 


\begin{abstract}
Using the Children's PTSD Inventory (CPTSD-I; Saigh, 1994), and Emotions Profile Index (EPI; Plutchik \& Kellerman, 1974) the study examined the frequency of post-traumatic stress disorder (PTSD), the level of aggression, and personality dimensions among juvenile offenders (JO). Ninety-seven JOs from Santa Clara County Juvenile Detention Center in California participated. Results indicated $57 \%$ of the JOs met the criteria for DSM-IV lifetime diagnosis of PTSD. Furthermore, a 2 × 2 MANOVA showed significant differences in aggression levels across groups. Specifically, significantly higher levels of aggression, both active and passive, were found among JOs with PTSD than those without PTSD. Also, an exploratory $9 \times 2$ MANOVA was run on the 9 EPI dimensions (i.e., 8 basic EPI traits and a bias score) by PTSD subgroup. While the overall MANOVA did not reach significance, significant univariate Fs emerged on 4 of the basic EPI dimensions (i.e., Trustful, Gregarious, Aggressive, \& Distrustful) and the Bias score.
\end{abstract}




\section{EMOTIONAL PROFILES OF JUVENILE OFFENDERS}

\section{WITH AND WITHOUT POST-TRAUMATIC STRESS DISORDER}

In 1981, the St. Louis Epidemiological Catchment Area surveyed 2,493

participants and found the prevalence rates for post-traumatic stress disorder (PTSD) to be $1 \%$ in the total population, about $3.5 \%$ in civilians who were exposed to physical attack and in nonwounded Vietnam veterans, and $20 \%$ in Vietnam veterans wounded in the war (Helzer, Robins, \& McEvoy, 1987). Dr. Hans Steiner, who is conducting a pilot study on juvenile offenders at the California Youth Authority, has preliminary findings of $36 \%$ of subjects meeting the DSM-III-R criteria for PTSD (personal communication, April 11, 1994). In addition, the pilot study for the present investigation found $25 \%$ of surveyed juvenile offenders meeting PTSD criteria (Schrack, 1994).

\section{PTSD Symptoms}

The characteristic symptoms of this disorder follow exposure to an extreme traumatic stressor. In general, PTSD symptoms fall into three categories: reexperiencing the trauma (e.g., nightmares, flashbacks, intrusive images or thoughts); avoidance (e.g., restricted range of affect, avoidance of activities, places, or people) and hyperarousal (e.g., problems sleeping, startle response). Examples of related symptoms differ across different age levels (Eth, 1990; Famularo, Kinscherff, \& Fenton, 1990). PTSD symptoms 
in children and adolescents may be different than those present in adults with the diagnosis due to developmental factors influencing symptom expression.

Clinicians must be careful to assess PTSD symptomatology in a developmentally sensitive manner. That is, topographically distinct PTSD symptoms may be present at different developmental levels, and care must be taken to ensure that the assessment of the presence/absence of PTSD is appropriate to the developmental level of the individual being assessed. If one expects to see symptoms characteristic of an adult with PTSD in a child or adolescent, the appropriate diagnosis of PTSD may not be made.

\section{Children's PTSD Symptoms}

Although much is known about adult symptomatology, less has been reported about symptoms seen in children with the disorder. There are, however, numerous child-related symptoms that should be assessed carefully. For example, children may exhibit reexperiencing symptoms in the following ways: engaging in repetitive play and talk, displaying inappropriate behaviors, and experiencing nightmares. Avoidance symptoms are likely to include dissociative reactions and regression to earlier developmental levels. Specific examples within this domain include regressive speech, secondary enuresis and/or encopresis, decreased range of affect, depression, avoidance behavior, loss of interest in usual activities, and difficulty making friends and engaging in 
social activities. Finally, numerous symptoms related to autonomic hyperarousal may be present. These include hypervigilance, startle reactions, increased irritability and aggression, anger outbursts, and difficulty sleeping and concentrating. Five additional symptoms have also been noted: significant weight loss or gain, academic difficulties, increased somatic complaints, suicidal ideation and/or intent, and immaturity (Deblinger, McLeer, Atkins, Ralphe, \& Foa, 1989). Although the basic categories of symptoms are consistent across developmental levels, the actual manifestation of symptoms within those categories may vary widely. Clearly, assessment tools that are sensitive to developmental variations of symptom expression are necessary to more adequately and accurately identify PTSD in children and adolescents.

\section{Literature Review}

Reviewing the literature conducted on juvenile offenders reveals a few studies focusing on traumatic stress in adolescents or the pathology arising from such stress. Atlas, Di Scipio, Schwartz and Sessoms (1991) found that adolescent students with conduct disorder and those with post-traumatic stress disorder had similar overt behavior problems, according to teacher reports. Many of the life events that occur in juvenile delinquents' lives also occur in children with post-traumatic stress disorder. Events such as physical or sexual abuse, witnessing family violence, community violence and gang 
activities, and witnessing violent death have all been reported in studies of juvenile offenders and children suffering from traumatic stress (Alijazireh, 1993; Farrington, 1989; Garbarino, Kostelny, \& Dubrow, 1991; Gidcz \& Koss, 1989; Kiser, Heston, Millsap, \& Pruitt, 1991; McLeer, Deblinger, Atkins, Foa, \& Ralphe, 1988; Muster, 1992; Silvern \& Kaersvang, 1989; Widom, 1991).

Rubinstein, Yeager, Goodstein, and Lewis (1993) found that "childhood sexual abuse, especially by females, was associated with adult sexual offenses" (p.262); therefore, sexually assaultive delinquents were at particularly high risk for subsequent violence. Kiser, Heston, Millsap, and Pruitt (1991) found children who experience physical or sexual abuse tend to exhibit heightened anxiety, hypervigilance, impaired impulse control, enuresis, sleep disturbances and socially inappropriate behaviors. Their coping strategies include: repetition of the assault in dreams, fantasy, aggressive play, self-destructive behaviors, and delinquency. Other common characteristics are depression, low self-esteem, and feelings of helplessness. Some of these symptoms overlap with PTSD-related symptoms, such as hypervigilance, enuresis, sleep disturbances, repetitious dreams or fantasy of assault, and aggressive play based on the trauma. Fifty-five per cent of the physically and/or sexually abused children in this study met DSM-III-R criteria for PTSD. Additionally, $70.8 \%$ of children who had received both physical and sexual abuse 
met the criteria, along with $90 \%$ of those physically abused for 5 or more years, and $2 / 3$ of the severely sexually abused children/adolescents.

Post-traumatic stress disorder was not associated with children until the 1980 's, and therefore not often discussed in prior research. Doyle and Bauer (1989) studied a residential setting for emotionally disturbed youth and found many youngsters who had been physically/sexually/emotionally abused or neglected also had trauma responses but had not been diagnosed with PTSD. The researchers documented a clinical team's reassessment process of 49 youth living at a residential placement home in Ohio. Ten of these youth were reclassified from their intake diagnosis to a new diagnosis of PTSD. Some of the common misdiagnoses were conduct disorder, adjustment disorder, attention deficit hyperactivity disorder, dysthymic disorder and major depression.

Further studies have indicated that $50 \%$ of subjects exposed to extreme stress have diagnosable PTSD (Kinzie, Sack, Angell, Manson, \& Rath, 1986; Mcleer, Deblinger, Atkins, Foa, \& Ralphe, 1988). Other studies recognize a higher percentage of diagnosis of PTSD (Eth \& Pynoos, 1983; Kiser, Ackerman, Brown, Edwards, McColgan, Pugh, \& Pruitt, 1983; Pynoos \& Nader, 1988).

Grossman, (1991) reported, " Traumatized infants and children may exhibit symptoms of aggressive, pain-seeking, and self-destructive behaviors resembling the 
so-called sadomasochism seen in adults" (p. 22). Farrington (1989) identified the following predictors of adolescent aggression, typically by age 8-10 years: impulsivity, lack of concentration, high daring behavior, lack of caring, nervousness and withdrawal, high troublesomeness, discipline difficulty, high laziness, low verbal and nonverbal IQ, separation from parents, convicted parents, and poor housing. These characteristics are consistent with those seen in juvenile offenders with PTSD.

Because aggression is found in both juvenile delinquents and some victims of PTSD, a special emphasis will be placed on the personality/emotional dimension of aggression within the juvenile offender population. This study will investigate if there is a factor of aggression/anger/hostility in those juvenile offenders who meet the DSM-IV criteria for PTSD. Schrack (1994) found $70 \%$ of the juvenile offenders with post-traumatic stress disorder in her study exhibited active-aggression, and that juvenile offenders with PTSD had substantially higher rates of active-aggression than passive-aggression (30\%). Fifty-two percent of juvenile offenders without PTSD exhibited active-aggression, and $57 \%$ exhibited passive-aggression. A person with an active-aggressive character dimension would be described as quarrelsome and aggressive, saying whatever is on her/his mind. She/he might display a high amount of overt anger. Others might characterize this individual as rebellious. A person displaying 
passive-aggressive behaviors would be characterized as stubborn, resentful, and sarcastic. She/he is overly critical and inclined to be rejecting of people and of others' ideas. She/he is likely to react to events rather than initiate them. She/he is typically perceived by others as hostile.

\section{Why is it important to look at the Juvenile Offender?}

Aggressive behaviors appear to be problematic and quite common in the juvenile offender population, yet treatment of aggression may not address the potential underlying factors (e.g., trauma) contributing to its expression. Focusing on PTSD in the juvenile offender population may allow us to identify and treat this potential determinant of aggression more effectively. The juvenile offender should be given the opportunity to receive clinical assessment and treatment of any underlying trauma(s) that may be contributing to her/his overall symptoms expression.

\section{Hypotheses}

Several hypotheses were advanced in this investigation in an attempt to replicate the findings by Schrack (1994), and to delineate more clearly the emotional profiles of juvenile offenders. They are as follows: 1) Juvenile offenders were expected to have a significantly higher frequency of PTSD than the general population rate of $1 \%$;2) Juvenile offenders with PTSD were expected to have a significantly higher level of 
active-aggression than juvenile offenders without a history of PTSD, and those juvenile offenders without PTSD were expected to have a significantly higher level of passive-aggression than those with PTSD; and 3) Juvenile offenders with and without post-traumatic stress disorder were expected to display significant differences in their emotional profiles.

$$
\text { Method }
$$

\section{Participants}

One hundred and one ( 84 male and 17 female) juvenile offenders (age 12 to 18 years; mean $=15.38$ years), housed at the Santa Clara County Juvenile Detention Center during May and June 1996, served as voluntary participants. All youth residing at the facility who spoke and understood English were invited to participate. Five male participants were deleted from the main analysis, yielding a total of 79 male participants. Three participants were omitted due to incomplete emotional profiles; 1 participant did not understand English; and l participant was omitted because of unintelligible responses (i.e., disorganized speech was present). The main analyses were run on 79 males and 17 females. Ethnic group affiliations were: 39 Hispanic, 16 White, 15 African-American, 11 Asian, 4 Filipino, 2 Native-American and 14 Mixed-Race or Other. Guardianship consent was requested and provided by the court for all participants. 


\section{Measures}

Participants were administered a series of three measures in interview format:

a) Background on Life Events (BLE) is a 41 -item questionnaire that identifies potential traumatic life situations and establishes categories of prior life events; gathers demographic information such as age, gender, and living environment; and identifies any concurrent diagnoses (see Appendix A).

b) Children's PTSD Inventory (CPTSD-I) DSM-IV Version (Saigh, 1994) is a screening device for the presence of DSM-IV criteria for post-traumatic stress disorder in children and adolescents. This is a 19 page structured interview, where subjects give a verbal response to each question. A simple yes or no answer is followed by the statement "Tell me about it." The actual verbal response from the youth is recorded. The year and month of any events stated by the youth are noted. The score of " 1 " represents a yes answer (PTSD positive response), and the score of " 0 " represents a no (PTSD negative response). Scoring is divided into seven areas using a criteria met approach: 1) exposure to a traumatic event; 2) situational reactivity; 3) trauma reexperiencing; 4) avoidance of stimuli associated with trauma and numbing; 5) increased arousal; 6) significant distress; and 7) total score equaling PTSD positive/negative. A specific diagnosis for PTSD is subdivided into: PTSD negative, acute PTSD, chronic PTSD, delayed onset PTSD, and 
no diagnosis (see Appendix B). The author is currently calculating reliability coefficients. Earlier versions of the CPTSD-I, based on DSM-III and DSM-III-R, reported a Kappa reliability coefficient of $.78(\underline{p}<.01)$, and the aggregate inter-rater level of agreement was $83 \%$ with a corresponding Kappa reliability coefficient of $.77(\mathrm{p}<.01)$. Written permission by the measure's author was granted to reproduce the Children's PTSD Inventory for this study.

c) Emotions Profile Index (EPI) (Plutchik \& Kellerman, 1974) is a 62-item forced choice test which is self administered. This pen and paper personality test is designed to yield information on eight basic personality dimensions: timid, aggressive, trustful, distrustful (i.e., passive-aggressive), controlled, dyscontrolled, gregarious, and depressed (see Appendix C). A bias score is calculated which indicates a tendency to pick socially desirable or undesirable items. Scores for the eight basic traits are converted to percentiles with scores at the 60th percentile considered "high" and those below the 40th percentile considered "low." Reliability coefficients for various scales range between .61 to .90 , and validity has been established by comparing the measure to the MMPI, the Edwards Personal Personality Schedule, the Gough Adjective Check List, the Barrett Impulsivity Scale, and the Cyde Mood Scale. Individual profiles may be interpreted in two ways: 1) according to interpretation of high and low scores on each dimension; and 2) according to 
interpretations of certain combinations of scores.

\section{Procedures}

Santa Clara County Juvenile Detention Center agreed to participate in this study and approached the court system for consent for those juvenile offenders volunteering to participate. Once judicial consent was given, unit counselors were contacted to invite juvenile offenders to participate in the project. Each participant met with trained interviewers who administered the series of measures. In order to control for differences in reading ability and ensure consistency in administration, the EPI instructions were administered orally by investigators according to a prewritten script (see Appendix D). Each juvenile completed all measures in one sitting. Each session lasted approximately one and a half hours. All materials were confined to the examining room.

In the event of unforeseen distress occurring to any of the youth, the interviewer gave each child oral information on contacting their unit counselor who could give them a referral to a "guidance counselor." The Santa Clara County Juvenile Detention Center has 24 hour counseling available.

To safeguard the privacy of participants, each juvenile was assigned a code number. All written material about subjects had identifying information removed. Data are reported in terms of groups (e.g., juvenile offenders with PTSD or juvenile offenders 
without PTSD). No individualized data are reported. All raw data from the BLE, CPTSD-I and EPI were kept in a locked file drawer and were available only to the research staff. Care was taken to explain all procedures prior to data collection to ensure that subjects felt comfortable with the situation. A full debriefing of the study took place following each completed interview session. Participants were informed that they had the right to refuse to answer any question and that they were able to stop participating at any time during the study. Soft drinks were offered to each participant as consideration for participation, as well as to relax the youth before the interview process began.

\section{Results}

\section{Design and Analysis}

To test hypothesis 1: a chi-square analysis was calculated to compare frequency of PTSD in the juvenile offender population to that of the general population. To test hypothesis 2: a 2 × 2 MANOVA was conducted which compared active and passive aggression levels in juvenile offenders with and without PTSD. To test hypothesis 3: a $9 \times 2$ MANOVA was used to analyze differences in the dimensions of the Emotions Profile Index across juvenile offenders with and without PTSD. Chi-square analyses were also completed to assess differences in the frequencies with which the two juvenile offender groups fell into high, normal and low categories on each dimension of the EPI. 
All statistical analyses, descriptive and inferential, were conducted using the Statistical Package for the Social Sciences (SPSS).

\section{Hypothesis 1}

Jivenile offenders will have a significantly higher frequency of PTSD than the general population rate of $1 \%$.

There is clear evidence that the juvenile offenders who participated in this study had experienced many potential traumatic events in their lives (see Table 1). Ninety-five participants had a history of at least one major life event that could cause a traumatic response. Ninety-two percent of the youth had two or more life events that would be classified as traumatic.

Fifty-seven percent of the juvenile offenders in this study met the DSM-IV criteria for Post-Traumatic Stress Disorder, currently or in their lifetime, and another $13.5 \% \mathrm{had}$ scores indicating they have many PTSD symptoms. Several chi-square analyses using different expectancies, based on previous findings, were conducted: using an expectancy of $1 \%$ (found in the general population), $\chi^{2}(1, \mathrm{~N}=96)=3072.7, \mathrm{p}<.0001$; utilizing an expectancy of $20 \%$ (found in Vietnam wounded veterans), $\chi^{2}(1, N=96)=83.44$, p <.0001, effect size: phi $=.87$; and using the expectancy of $25 \%$ (see Schrack, 1994), $\chi^{2}(1, \mathrm{~N}=96)=53.39, \mathrm{p}<.0001$, effect size: $\mathrm{phi}=.56$. Thus, there appears to be a 
Table 1

Summary of Life Experiences of Juvenile Offenders

\begin{tabular}{lll} 
& & Y e s \\
\hline 1. & $\begin{array}{l}\text { Have you ever experienced a major accident? } \\
\text { (car, plane, train, bus, boat, or sport) } \\
\text { *mode = car }\end{array}$ & $46.5 \%$ \\
& $30.0 \%$
\end{tabular}

2. Have you ever seen a person die?

3. Have you ever been physically or sexually abused? $26.5 \%$

4. Have you ever been a victim of terrorism, kidnapping or violent assault?

5. Have you ever experienced a natural disaster?

(earthquake, tornado, hurricane, fire, flood or tidal wave)

${ }^{*}$ mode $=$ major earthquake

6. Adolescent past diagnosis of a major disorder or illness.

$36.3 \%$ (see Background on Life Events)

Anxiety Disorder

Count

Borderline Person. 4

Bipolar Disorder 1

Obsessive-compulsive Disorder

Major Depression

3

Panic Disorder 16

PTSD past

Schizophrenia

2

Migraine Headache

Cancer 15

Tuberculosis 
significantly higher rate of PTSD in this juvenile offender sample than in the general population.

\section{Hypothesis 2}

Based on the results of Schrack (1994), Juvenile offenders with PTSD will have a significantly higher level of active-aggression than juvenile offenders without a history of PTSD, and those juvenile offenders without PTSD will have a significantly higher level of passive-aggression than those with PTSD.

To replicate the results by Schrack (1994), a 2 x 2 MANOVA was run on two dependent measures: active-aggression and passive-aggression by PTSD subgroup. An overall significant MANOVA was obtained using Pillais Test, $\mathrm{F}=3.99, \mathrm{p}<.022$ (power $=.70$; effect size $=.08$ ). In addition, significant univariate F's were obtained for the active-aggression variable with $\underline{\mathrm{F}}(1,94)=7.64, \mathrm{p}<.007$ (power $=.78$ ); and for the passive-aggression variable with $\underline{\mathrm{F}}(1,94)=3.99, \underline{\mathrm{p}}<.049$ (power $=.50$ ). Iuvenile offenders with PTSD had significantly higher scores on both the active-aggression and passive-aggression (see Distrustful Dimension on EPI) dimensions than youth without PTSD. On the active-aggression dimension, the mean score for the with PTSD group was $74.75(S D=26.20)$ while the mean score for the without PTSD group was 58.64 (SD $=31.64)$. On the passive-aggressive scale, the mean score for the with PTSD group was 
$55.02(\mathrm{SD}=31.70)$; while the mean score for the without PTSD group was $42.32(\mathrm{SD}=$ 29.62). A post hoc analysis discovered that girls significantly used passive-aggression more than boys, $\chi^{2}(1, \mathrm{~N}=96)=6.93, \mathrm{p}<.03$, effect size $=.07$. Steiner and Feldman, 1995 also found significant differences in defense mechanism styles between girls and boys. Hypothesis 3

There will be significant differences in the emotional profiles of jwvenile offenders with and without post-traumatic stress disorder.

An exploratory $9 \times 2$ MANOVA was run on the eight basic traits and bias score of the Emotions Profile Index (continuous scores) by PTSD subgroup. The overall non-significant MANOVA was obtained using Pillais test, $\underline{F}=1.58, \underline{p}>.135$ (power $=.70$; effect size $=.14 ; \mathrm{N}=96:$ With PTSD $=55$, Without PTSD $=41$ ). Five significant (Distrustful, Trustful, Gregarious, Aggressive, and Bias) and four non-significant (Depressed, Dyscontrolled, Timid and Controlled) univariate F's were obtained (see Table 2).

Individual chi-square tests were performed on the eight basic traits and bias score of the Emotions Profile Index (categorical scores) by PTSD subgroup (see Table 3) with three significant (Trustful, Gregarious, and Bias), three approaching significance (Distrustful, Aggressive, Timid), and three non-significant (Controlled, Dyscontrolled, and 
Table 2

Emotions Profile Index MANOVA Results

\section{Mean Score (Standard Deviation)}

\begin{tabular}{|c|c|c|c|c|c|}
\hline Dimension & With PTSD & Without PTSD & $\mathrm{F}$ & Significance & Power \\
\hline Trustful & $27.25(26.58)$ & $47.73(30.41)$ & 12.32 & $\mathrm{p}<.001^{* *}$ & .93 \\
\hline Gregarious & $33.45(25.98)$ & $50.95(26.31)$ & 10.54 & $\mathrm{p}<.002^{*}$ & .89 \\
\hline Bias & $25.63(26.18)$ & $42.56(30.61)$ & 08.49 & $\mathrm{p}<.004^{*}$ & .82 \\
\hline Aggressive & $74.75(26.20)$ & $58.42(31.64)$ & 07.64 & $\mathrm{p}<.007^{*}$ & .77 \\
\hline Distrustful $^{1}$ & $55.02(31.70)$ & $42.32(29.62)$ & 03.99 & $\mathrm{p}<.049^{*}$ & .50 \\
\hline Depressed & $72.58(24.52)$ & $65.20(26.70)$ & 01.98 & $\mathrm{p}>.163$ & .28 \\
\hline Dyscontrolled & 56.85 & $48.05(26.02)$ & 02.70 & $\mathrm{p}>.104$ & .37 \\
\hline Timid & $38.64(26.75)$ & $46.78(30.73)$ & 01.92 & $\mathrm{p}>.169$ & .28 \\
\hline Controlled & $37.71(26.89)$ & $39.27(28.53)$ & 00.07 & $\mathrm{p}>.785$ & .05 \\
\hline
\end{tabular}

Notes: $N=96:$ With PTSD $(n=55)$ : Without PTSD $(n=41)$

** significant at the .001 level

* significant at the .05 level

' Distrustful Dimension $=($ Passive-aggression scale $)$

High Score: This person tends to be stubborn. resentful, and sarcastic. S/he is overly critical and tends to be rejecting of people and of ideas. S/he is most likely perceived by others as a hostile person. Another description of her/him might be "passive-aggressive," or guarded.

\begin{tabular}{lcc} 
& \multicolumn{2}{c}{ Sample size required to detect at 05} \\
\cline { 2 - 3 } Power & $\begin{array}{c}\text { F }(d f=I) \\
\text { "medium" effect }\end{array}$ & $\begin{array}{c}\text { F }(d f=I) \\
\text { "small" effect }\end{array}$ \\
\hline .15 & 10 & +5 \\
.20 & 10 & 65 \\
.30 & 20 & 105 \\
.40 & 25 & 150 \\
.50 & 30 & 200 \\
.60 & 40 & 250 \\
.70 & 50 & 300 \\
.80 & 65 & 400 \\
.90 & 85 & 550
\end{tabular}

Based on J. Cohen. Stanstical Power Analysts for the Behavoral Sciences, Academic Press. New York. 1977. 
Table 3

\section{Emotions Profile Index Chi-square Results}

\begin{tabular}{|c|c|c|c|c|c|c|c|c|c|}
\hline \multirow{3}{*}{$\begin{array}{l}\text { Dimension } \\
\text { Trustful }\end{array}$} & \multicolumn{3}{|c|}{ With PTSD } & \multicolumn{3}{|c|}{ Without PTSD } & Chi-Souare & \multicolumn{2}{|c|}{ Significance nhi coefmedent $\phi$} \\
\hline & High & Norme & ILow & High & Norm & al Low & & & \\
\hline & $16 \%$ & $09 \%$ & $75 \%$ & $34 \%$ & $17 \%$ & $49 \%$ & $\chi^{2}(2)=6.75$ & $\mathrm{p}<.034^{*}$ & .27 \\
\hline Gregarious & $18 \%$ & $22 \%$ & $60 \%$ & $32 \%$ & $34 \%$ & $34 \%$ & $\chi^{2}(2)=6.32$ & $\mathrm{p}<.042^{*}$ & .26 \\
\hline Bias & $16 \%$ & $07 \%$ & $76 \%$ & $34 \%$ & $15 \%$ & $51 \%$ & $\chi^{2}(2)=6.59$ & $\mathrm{R}<.037^{*}$ & .26 \\
\hline Aggressive & $76 \%$ & $09 \%$ & $15 \%$ & $56 \%$ & $09 \%$ & $34 \%$ & $x^{2}(2)=5.30$ & $\mathrm{p}>.068^{?}$ & .24 \\
\hline Distrustful & $+6 \%$ & $24 \%$ & $31 \%$ & $27 \%$ & $20 \%$ & $54 \%$ & $\chi^{2}(2)=5.35$ & $\mathrm{p}>.069^{?}$ & $.2 t$ \\
\hline Depressed & $69 \%$ & $15 \%$ & $16 \%$ & $66 \%$ & $17 \%$ & $17 \%$ & $x^{2}(2)=0.14$ & $R>.933$ & .14 \\
\hline Dyscontrolled & $H \%$ & $27 \%$ & $29 \%$ & $39 \%$ & $20 \%$ & $+2 \%$ & $x^{2}(2)=1.76$ & $\mathrm{p}>.+16$ & .14 \\
\hline Timid & $22 \%$ & $22 \%$ & $56 \%$ & $+2 \%$ & $10 \%$ & $+9 \%$ & $\chi^{2}(2)=5.31$ & $\mathrm{p}>.070^{?}$ & .24 \\
\hline Controlled & $18 \%$ & $27 \%$ & $55 \%$ & $29 \%$ & $15 \%$ & $56 \%$ & $\chi^{2}(2)=2.99$ & $p>.225$ & .18 \\
\hline
\end{tabular}

Notes: $\quad N=96:$ With PTSD $(n=55)$ : Without PTSD $(n=41)$

* significant at the .05 level

' approaching significance

\begin{tabular}{cl} 
Interpreting & Cohen's effect size \\
\hline phi coefficient $\phi$ & a "small" effect produces a $\phi$ of .10 \\
$\chi^{2}$ & a "medium" effect produces a $\phi$ of .30 \\
$\phi=\sqrt{ }$ & a "large" effect produces a $\phi$ of .50 or greater
\end{tabular}


Depressed). While juvenile offenders' scores were distributed across all categories (i.e., high, normal, and low) on all dimensions, only $10 \%$ to $26 \%$ of all scores fell into the normal range on any one dimension. For the most part, juvenile offenders scores fell into either the high range or low range on each dimension regardless of the PTSD subgroup. Descriptions for personality traits on the EPI are assigned to scores that fall into either a "High" range (above 60th percentile) or "Low" range (below 40th percentile). Personality interpretations are also available for certain combinations of scores which will be discussed later.

\section{Analyses of Demographic Variables}

A significant difference was found for distribution of ethnicities across PTSD subgroups, $\chi^{2}(4, \mathrm{~N}=96)=17.40, \mathrm{p}<.0016$, effect size $=17$. In this sample of juvenile offenders, Hispanic, and Mixed-raced or Other group participants were more represented in the with-PTSD than the without-PTSD group, while the reverse was true for Asian-American and White participants; African-American participants were equally distributed across both groups (See Table 4). The ethnicity rates and gender distribution appear to be representative of the juvenile offenders housed at the Santa Clara County Juvenile Detention Center during May and June, 1996. The total facility housed approximately 245-260 juvenile offenders on any given day. There was a very unequal sex 
Table 4

Frequency of PTSD by Ethnicity

With PTSD Without PTSD

Ethnicity (\% of Ethnic Group) (\% of Ethnic Group)

African-American $6 \quad(50.0 \%)$ $6 \quad(50.0 \%)$

Asian $2 \quad(18.2 \%)$

$9 \quad(81.8 \%)$

Filipino*

$3 \quad(75.0 \%)$

I $(25.0 \%)$

Hispanic $25 \quad(65.8 \%)$

$13 \quad(34.2 \%)$

Native-American*

$2 \quad(100 \%)$

$0 \quad(0 \%)$

White

$5 \quad(31.3 \%)$

$11 \quad(68.7 \%)$

Mixed-Race/Other

$12 \quad(92.3 \%)$ 55

$1 \quad(7.7 \%)$

41

Notes: $\mathrm{N}=96$

* these groups were converted to mixed-race/other category in Chi-square calculations due to expected frequencies were smaller than 5. 
distribution in the juvenile offender sample, with 17 females and 79 males; thirteen (76\%) of the females met DSM-IV criteria for PTSD, whereas 43 (54\%) of the males met DSM-IV criteria. Thirty-one percent of the juvenile offenders were in juvenile hall for the first time; the range of the times that the juveniles had come before the juvenile court was 1 to 20 , with $61.5 \%$ having come before the court 3 times or less, according to self-report. Yet, $48 \%$ of the juvenile offenders who met DSM-IV criteria for PTSD had come before the court more than 3 times. Self reports by the youth indicated that the earliest age that someone came before the juvenile court was 8 years old; the ages of 13 years, 14 years, and 15 years, were the most common ages for first offense. The age of first offense did not differ significantly across PTSD subgroups. Forty-three percent of the youths lived with two adults and $32 \%$ of the youths lived in a single adult household. Youth were not sharing the house with any other children $24 \%$ of the time, shared their home with one other child $29 \%$ of the time; two other children $16 \%$ of the time; and three other children $10 \%$ of the time. None of the youth claimed to share their house with more than six children. The number of adults or children in the household did not differ significantly across PTSD subgroups in this study.

The background questionnaires collected many traumatic situations to which the juvenile offenders had been exposed which could be linked to meeting the criteria for 
PTSD. A significantly greater number of juvenile offenders with PTSD disclosed a history of being a victim of terrorism, kidnapping, or violent assault; $\chi^{2}(1, \mathrm{~N}=96)=17.87$, $\mathrm{p}<.0001$, effect size $=.17$; or having a past history of a Major Depression; $\chi^{2}(1, N=96)=$ $7.16, \mathfrak{p}<.0075$, effect size $=.07$, admission of being physically or sexually abused approached significance: $\chi^{2}(1, \mathrm{~N}=96)=3.38, \underline{p}<.0658$, effect size $=.03$.

\section{Discussion}

\section{Hypothesis One.}

Hypothesis one, that juvenile offenders were expected to have a significantly higher frequency of PTSD than that of the general population (1\%), was clearly supported. In this study it was found that $57 \%$ met a current or lifetime criteria for PTSD. Because of a paucity of juvenile offender PTSD research, a comparison was made with the published expectancies of the Vietnam wounded-veteran rate of PTSD (20\%). The results were robust and left little doubt of an abnormally high rate of post-traumatic stress disorder in the juvenile offender population. Subsequent analyses were run to replicate the 25\% PTSD rate in juvenile offenders found in Schrack (1994). In this earlier study, along with the $25 \%$ of the juvenile offenders who met the DSM-III-R criteria for PTSD, there was an additional $25 \%$ who could have potentially been diagnosed with PTSD but didn't meet the measure's (PTSD-I, Watson, Juba, Manifold, Kucala, \& Anderson, 1991) 
stringent severity criteria. In the present study, using a new measure (CPTSD-I, Saigh, 1989), the finding of $57 \%$ of the participatory juvenile offenders meeting DSM-IV criteria for PTSD currently or in their lifetime, clearly indicates that this is a special group which seems to be highly affected by this disorder.

Limited published research has been conducted on the juvenile offender population and post-traumatic stress disorder. Most information in this area is gleaned from journal articles on related subjects, such as crack dealing \& PTSD (Weisman, 1993); children's exposure to violence (Bell \& Jenkins, 1993; Cooley, Tumer, \& Beidel, 1995; Eth \& Pynoos, 1983; Fitzpatrick \& Boldizar, 1993; Lorion \& Saltzman, 1993; Martinez \& Richters, 1993; Osofsky, Wewers, Hann, \& Fick, 1993; Richter, 1993; Richter \& Martinez, 1993); physical and sexual abuse (Doyle \& Bauer, 1989; Gidez \& Koss, 1989; Kiser et al., 1988, 1991; McLeer, Deblinger, Atkins, Foa, \& Ralphe, 1988; Muster, 1992; Rubinstein, Yeager, Goodstein, \& Lewis, 1993); adolescence and trauma (Brent et al., 1995; Hubbard, Realmuto, Northwood, \& Masten, 1995; McClosey, Southwick, Fernández-Esquer, \& Locke, 1995; Stallard \& Law, 1993; Steiner \& Feldman, 1995; van der Kolb, 1985); and substance abuse and delinquents (Riggs, Baker, Mikulich, Young, \& Crowley, 1995). This thorough review of the literature has linked post-traumatic stress disorder with $5 \%$ to $59 \%$ of children who witnessed or were victims of violent or 
traumatic events.

Riggs, Baker, Mikulich, Young, and Crowley (1995), for example, studied juvenile delinquents with conduct disorder and substance dependency. They found depression was often comorbid with conduct disorder. Depressed participants also had more substance dependency diagnoses and were more likely to have attention-deficit hyperactivity disorder, PTSD, and anxiety disorders. Forty percent of their depressed, substance-dependent delinquents and $15 \%$ of the non-depressed, substance-dependent delinquents met DSM-IV criteria for PTSD.

Fitzpatrick and Boldizar (1993) examined the relationship between community violence and PTSD in low-income African-American youth living in a urban area. The violent community events disclosed by these youth were very similar to those disclosed by the juvenile offenders of our study: being threatened, chased and/or beaten, sexually assaulted, attacked with a knife, seriously wounded, shot or shot at, or a witness to violence and/or murder. The Fitzpatrick and Boldizar study found that $27.1 \%$ of the youth met PTSD criteria.

Weisman (1993) found that $9 \%$ of the youth who dealt crack and also carried guns for protection and respect met PTSD criteria after witnessing the death of friends or family members. Youth who live with violence on a daily basis may cope with the death of 
peers by denial or romanticizing the violent life style.

None of the literature reviewed, with the exception of the Hubbard, Realmuto, Northwood, and Masten (1995) study, came close to the 57\% of PTSD in this juvenile offender population. It should be noted that the CPTSD-I, the measure used in the present study, was not administered in previous investigations. Hubbard et al., examined 59 Cambodian young adults who survived massive trauma as children (the sample now lived in the United States). Their findings showed that $24 \%$ met DSM-IV criteria for current PTSD, and 59\% met lifetime PTSD criteria.

Yet another factor that may impact the frequency of PTSD is the composition of the juvenile offender group. The juvenile offenders housed in the Juvenile Detention Center are awaiting court dates; or are not amenable to ranch placement; or serving a lighter sentence than the youth at California Youth Authority (CYA). Youth at the Juvenile Detention Center, however, are detained for more serious offenses than youth on house arrest. Steiner's (1994) preliminary findings of $36 \%$ of CYA offenders having met DSM-III-R criteria for PTSD might have had a smaller percentage of juvenile offenders meeting criteria than the present findings because his population is a subset of our population. 


\section{Hypothesis Two.}

Hypothesis 2 was based on the 1994 findings by Schrack. The present investigation partially supported the hypothesis that: 1) juvenile offenders who have PTSD would have a significantly higher level of active-aggression than juvenile offenders without a history of PTSD, and 2) those juvenile offenders without PTSD would have a significantly higher level of passive-aggression than those with PTSD. In the present study, part 1 of the hypothesis was supported, but part 2 was not. The overall MANOVA tests for each study, 1994 and 1996, were significant. Active-aggression mean scores were similar for both PTSD subgroup in both years $(1994,1996)$, but the passive-aggression scores are notably different. In Schrack (1994), the without-PTSD subgroup had a higher mean score (61.86) on the Distrustful Dimension (passive-aggression score) than the with-PTSD subgroup (34.00), whereas in the present study the reverse is true; the juvenile offenders with PTSD have a higher mean score (55.02) than those without PTSD (42.32; see Table 5).

The present data must be interpreted very cautiously due to the dramatic discrepancy in passive-aggressive tendencies between the two studies. Demographic and life experience differences between the two studies' participants may be responsible for the differences noted here on this one dimension. In the prior study, $57 \%$ of the youth lived 
Emotional Profiles of PTSD 27

Table 5

Aggression Levels in 1994 versus 1996

MANOVA Result:

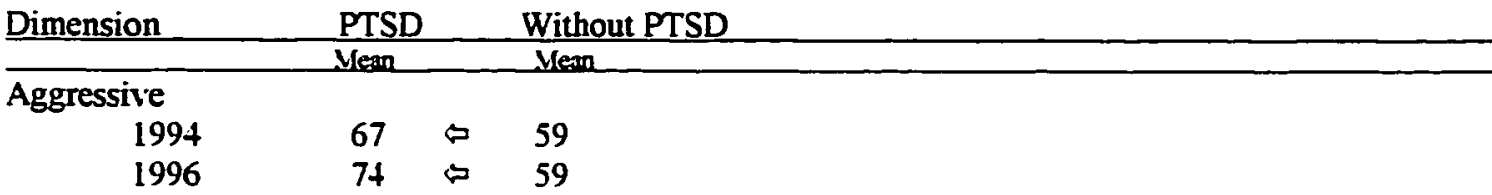

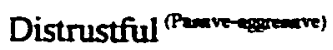

$\begin{array}{llll}1994 & 35 & \leftarrow & 62 \\ 1996 & 54 & \leftarrow\end{array}$

Chi-square Results:

Dimension

Aggressive

1994

1996

Distrustful (Pamverenave)

1994

1996
PTSD

High Normal low

$70 \% \quad 20 \% \quad 10 \%$

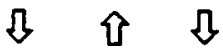

$76 \% \quad 09 \% \quad 15 \%$
Without PTSD

High Normal low

$52 \% \quad 10 \% \quad 38 \%$

及 $\hat{\mathrm{V}} \hat{\mathrm{v}}$

56\% $09 \% \quad 34 \%$

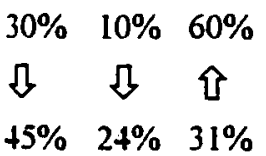

$57 \% \quad 19 \% \quad 24 \%$

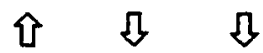

$27 \% \quad 20 \% \quad 54 \%$ 
with two adults and $25 \%$ lived in single parent households, whereas in the present study, the rates were $43 \%$ and $32 \%$, respectively. The proportion of participants from different ethnic groups shifted slightly, with each ethnic group 5\% to $6 \%$, up or down, between studies (e.g., African-American $1994=20 \% ; 1996=15 \%$ ). The present study sample had more participants: seeing someone die ( $54 \%$ vs. $36 \%$ ), disclosing physical or sexual abused ( $26.5 \%$ vs $12.5 \%$ ), having been a victim of terrorism, kidnapping, or violent assault ( $53.5 \%$ vs $43.6 \%$ ), and reporting more past diagnoses of a major disorder or illness (36.3\% vs $20 \%$ ). Multiple traumas were up $7 \%$, with $92 \%$ of the participants in the present study having been exposed to two or more potential traumatic experiences. Both active and passive aggression are higher in this study, and more direct victim violence has been reported.

Clinical studies have attributed risk factors for violence to include: poverty, high population density, poor housing, high unemployment, hopelessness, lack of life options, adolescent physical and psychological changes with puberty, being male, early exposure to family violence (Fitzpatrick \& Boldizar, 1993; Martinez \& Richters, 1993; Spivak, Hausman, \& Prothrow-Stith, 1989). Osofsky, Wewers, Hann, and Fick (1993) found a significant relationship between exposure to community violence, the incidence of family violence, and the overall stress symptoms observed in the children. 
One might speculate that the juvenile offenders from large urban areas are in the high risk group for violence because of living in or hanging-out in environments of pervasive violence, familiarity with victims and perpetrators, repeated exposure to traumatic events, coping with street drugs and alcohol, while also dealing with the physical and psychological changes of puberty. The juvenile offender with PTSD comprises three high stress groups: the adolescent, the juvenile offender, and the person with PTSD. It makes intuitive sense that with these risk factors, high levels of aggression, both active and passive, would be present. First, adolescents have a tendency to emotionally overreact with a less powerful stimulus trigger (Olson, 1984). Anger and frustration are common companions in most teen-agers' homes. "Relationships between delinquent adolescents and their parents are frequently characterized by mutual hostility. The parents of delinquents are more likely to ignore or reject their children, to have personal problems of their own, and to have police records" (Biehler \& Hudson, 1986, p.610). Second, juvenile offenders walk a thin line with violence whenever criminal acts are involved; the juvenile violent arrest rate has increased $53 \%$ between 1985 and 1993 (Hill, 1995). Data prepared by the National Institute of Justice found $55 \%$ of juvenile offenders carry a gun. Also, 30\% - 43\% of the juveniles arrested in 1993 tested positive for drugs (Hill, 1995). Thirdly, PTSD sufferers are trying to make sense out of 
dangerous and traumatic events. " The symptoms of PTSD are a function of the person's attempt to cope with events that cannot be experienced, processed and mastered in an adaptive manner using the usual modes of coping" (Peterson, Prout, \& Schwartz; 1993, p.42). Coping skills are reduced while reexperiencing the trauma(s), numbing and limited affects are common, and physical arousal often takes a toll on a person's nerves. Irritability or outbursts of anger are considered one of the symptoms of increased arousal. Fitzpatrick and Bodizar (1993) found that $44.7 \%$ of low-income, urban, African-American youth expressed the PTSD symptom of irritability.

Maiuro and Eberle (1989) recounted the 1988 International Society for Research on Aggression in Wales, United Kingdom. In some cases, violent behavior was distinguished by self-reinforcement, the performance of the violent "act as having an increase in arousal, excitement, positive feedback regarding self-efficacy, or intermediate reinforcement toward the goal of victim submission or defeat" (p.5). This might explain the victim crimes and numerous large street fights disclosed by many gang-associated juvenile offenders. Another study reported by Maiuro and Eberle (1989), from Finland, found that boys were more verbally and physically aggressive, while girls were more indirect and passive aggressive. Our study supports that girls described themselves as more passive-aggressive than boys (girls $=65 \%$ vs boys $=32 \%$ ). 
Lorion and Saltzman (1993) expressed that:

children of violence may despairingly conclude that, time available notwithstanding, they have neither the resources nor the likelihood of achieving lasting or socially approved outcomes. For them, socially unacceptable and risky, albeit immediately rewarding, alternatives may become highly attractive. In turn, their choices may perpetuate that environment of violence that limited their options (p.56).

Social learning theory, which stresses the significance of observation and imitation, should not be overlooked. Modeled parent and community members' behaviors are transferred to the childs' behaviors. Many of the parents of these juvenile offenders are also exposed to direct and indirect violence (Lorion, \& Saltzman, 1993; Martinez \& Richters, 1993; Osofsky, Wewers, Hann, \& Fick (1993). In one study, Richters and Martinez (1993) found an extraordinary increase in community violence. In urban areas, victimization and witnessing of violence involved family members ( $13 \%)$, friends $(50 \%)$, acquaintances ( $12 \%)$ and strangers ( $25 \%)$. Modeling of violent behaviors appears to have resulted in many adolescent acts of violence. A teenager, frustrated to the breaking point, may grab a gun and start shooting, as seen on television, in a movie (Biehler \& Hudson, 1986), or in their own communities (Osofsky, Wewers, Hann, and Fick (1993). 
Aggressive behaviors are frequently reinforced in the homes where there are excessively aggressive children. Parents of these children were likely to tease or make demands of the child. When the child reacted with anger, the reactions of other family members (laughter, attention, compliance with the child's demands, or aggression) often lead to a reciprocal reinforcement pattern (Patterson as cited in Biehler \& Hudson, 1986).

The results from both the present study and Schrack (1994) reveal that juvenile participants who meet criteria for PTSD may be more likely to exhibit overt aggressive behaviors. This high rate of aggression, however, is not unique to the PTSD populations, as high rates of active-aggression are also found in the without-PTSD juvenile offenders (56\%). Further study is needed before definitive statements regarding aggressive behavior and PTSD within the juvenile offender population can be made. The trends noted, however, indicate that further study of this question and possible association is clearly warranted.

Hypothesis 3: Summary results and explanations for findings

A chi-square analysis was conducted to identify any personality traits that relate to post-traumatic stress disordered juvenile offenders. Personality traits are linked to scores in the high range (above 60th percentile) and low range (below the 40th percentile). The Personality descriptions are based upon traits described in Plutchik and Kellerman (1974). 
Chi-square significance was found in three dimensions: Trustful, Gregarious and the Bias score. Three additional dimensions approached significance: Aggressive, Distrustful, and Timid (see Table 6).

When looking at the MANOVA and Chi-square analyses together, it appears that a larger sample would have been useful. This study was planned based on a medium effect size, but the effect size ran somewhere between small and medium (see Table 3). A power analysis revealed the power ran below .80 (the suggested power setting by Cohen and others) on five out the nine EPI trait (see Table 2).

An exploratory MANOVA was also conducted to discover any difference that may exist in personality traits. Whereas the overall analysis was not conclusive, evidence for personality characteristics could be presumed if the PTSD subgroup was known. Five significant dimensions were identified: Trustful, Gregarious, Aggressive, Bias and Distrustful. Juvenile offenders with PTSD were significantly more likely to score lower than the without PTSD subgroup on the Trustful, Gregarious and Bias dimensions. Furthermore, juvenile offenders with PTSD were significantly more likely to score higher than the without PTSD subgroup on the Aggressive and Distrustful dimensions.

Figure 1 further depicts these data trends with an additional comparison to normal male high school students. Notice that the average male high school student falls below 
Table 6

\section{Personality Traits of Juvenile Offenders with PTSD}

\begin{tabular}{|c|c|c|}
\hline Dimension & Status & Description of personality trait \\
\hline Trustful $* x$ & Low & $\begin{array}{l}\text { This person tends to be unaccepting. distrustful. } \\
\text { disobedient and not very gullible. He does not take } \\
\text { things at face value. }\end{array}$ \\
\hline Gregarious *x & Low 505 & $\begin{array}{l}\text { This person tends to be unsociable. unfriendly. unaffectionate } \\
\text { and introverted. He tends to be isolated and withdrawn. }\end{array}$ \\
\hline Bias Scale $* x$ & Lowis & $\begin{array}{l}\text { This person has a tendency to describe himself in socially } \\
\text { undesirable ways. }\end{array}$ \\
\hline Aggressive *? & $\mathrm{High}^{\text {in. }}$ & $\begin{array}{l}\text { This person tends to be quarrelsome and aggressive. He tend } \\
\text { to say whatever is on his mind. He has a lot of anger and } \\
\text { expresses it overtly. He tends to blow off steam with people } \\
\text { around. People might describe him as rebellious. }\end{array}$ \\
\hline Distrustful $* ?$ & $\mathrm{High}^{\text {tses }}$ & $\begin{array}{l}\text { This person tends to be stubborn. resentful and sarcastic. He } \\
\text { is overiy critical and tends to be rejecting of people and of } \\
\text { ideas. He is most likely perceived by others as a hostile } \\
\text { person. Another description of him might be } \\
\text { "passive-aggressive." or guarded. }\end{array}$ \\
\hline Depressed & High $^{695}$ & $\begin{array}{l}\text { This person is depressed sad and gloomy. He is dissatisfied } \\
\text { with aspects of his life. He feels deprived and is probably } \\
\text { pessimistic. Extremely high scores may be associated with } \\
\text { suicidal tendencies. }\end{array}$ \\
\hline
\end{tabular}

Dỵscontrolled $\quad$ High $^{\text {the }}$

This person tends to be impulsive. He likes to try new things and have netw experiences. He likes surprises. He might also be described as adventurous or curious.

Timid? Low

This person is less cautious and fearful than the average person. He tends to take risks and can easily get into trouble. He will do things that are dangerous and not in his own best interests. Extremely low scores may indicate impaired reality testing.

Controlled Low $\quad$ This person tends to live his life on a day-to-day basis. He does not plan for the future. He tends to be disorganized in his thinking and in his activities. He has very little need for orderliness. He tends to have little self-control.

Note: "Significant difference MLNOVA

${ }^{*}$ Significant difference Chi-square

P. Aproaching Significance Chi-Square 


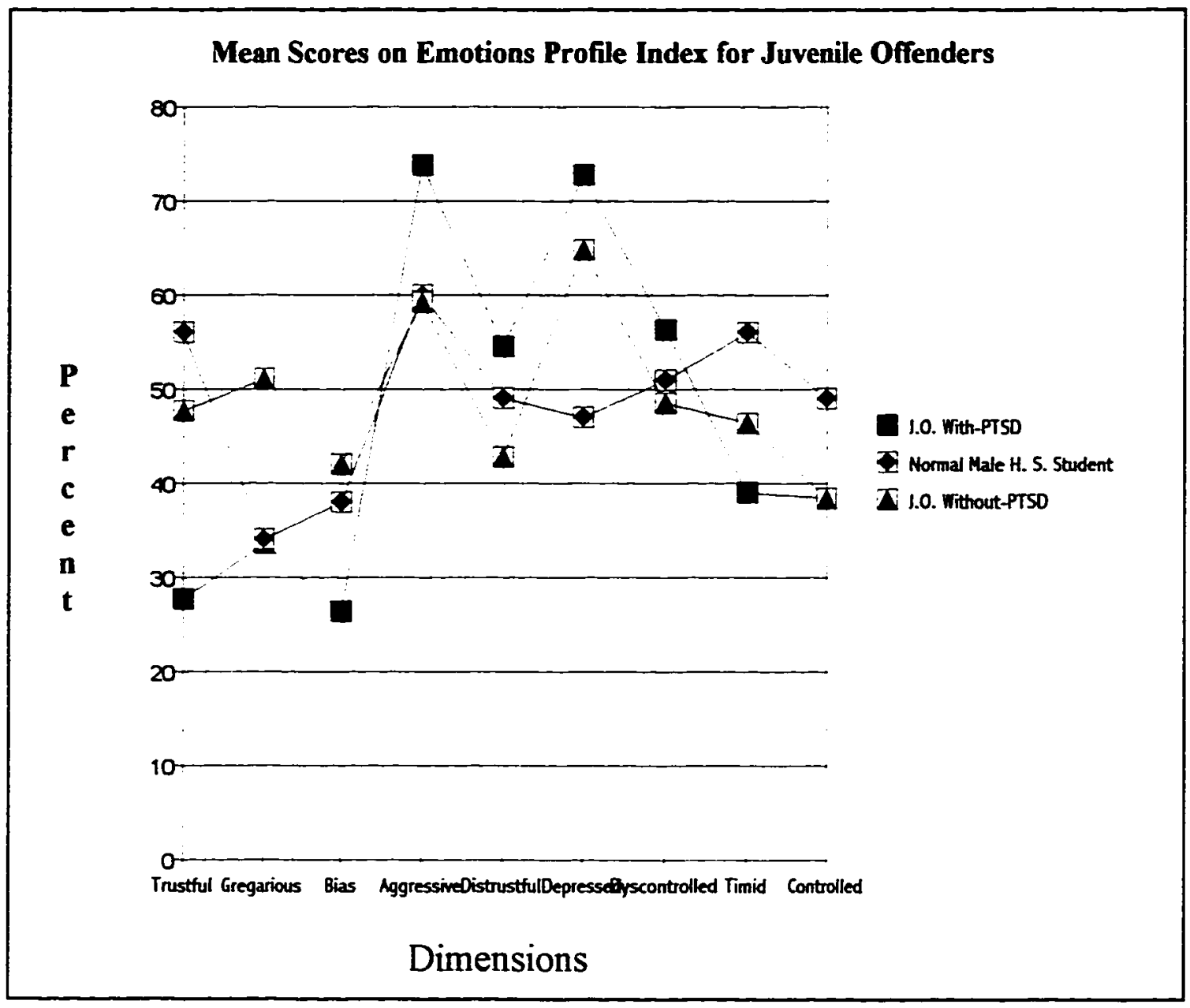

Figure 1. The mean scores for Emotions Profile Index's personality dimensions are based on continuous scores.

Raw scores for the eight basic traits and the bias score are converted to percentiles, with scores at or above the $60^{\text {th }}$ percentile considered "high" and those at or below the $40^{\text {th }}$ percentile considered "low". 
the normal range in the Gregarious and Bias dimensions. The juvenile offenders without PTSD deviate from the normal range in only two areas: their mean score is in the high range for Depressed and the low range for Controlled. Juvenile offenders with PTSD, in contrast, deviate from the norm in seven of the nine areas, as noted below.

Personality characteristics such as low gregariousness, low trustfulness, high aggression, low bias scores (describing oneself in socially undesirable ways), high passive-aggression (distrustful dimension), and low timidity (risk taking, self defeating, impaired reality testing) are easily associated with PTSD. Descriptions normally identified with the low gregarious dimension include; unsociable, unfriendly, unaffectionate, introverted, and isolated and withdrawn. The adolescent's need for peers in our study seemed to override the unsociability of the group. Some of PTSD-juvenile offenders admitted lower social contact, but by far they still maintained their close friendships or gang contacts. Interviews disclosed that positive affect was regulated by drug and alcohol intake by many juvenile offenders on a regular basis. Depression still seems to have been a greater emotional factor with $69 \%$ of the with PTSD scoring in the high range.

Having low trustfulness would be common for anyone who had lost a safe world. Traumatic events by their own nature leave one feeling vulnerable and helpless. How one appraises the world changes. Things are no longer what they once seemed. This lack of 
trust in PTSD patients has also been noticed by other researcher (Krystal, 1993;

Macksoud, Dyregrov, \& Raundalen, 1993). Whether that trust is lost because individuals perpetrated the events, or because family or self could not keep them safe, the personal vulnerability lingers. If the trauma is man made, and comes from a familiar person, betrayal is also felt.

Lowered self-esteem appears to exist concurrently with this lowered trust. Guilt, culpability, shame, and helplessness are often intermingled with lowered self-esteem in trauma survivors. Mistrust, along with feelings of betrayal, and a disrupted self-image, has been found to be a secondary feature to PTSD by Peterson, Prout, and Schwartz (1993), whereas irritability and outbursts of anger/rage are consider primary symptoms. Not all PTSD sufferers display every symptom. So why do so many juvenile offender display high levels of aggression? Perhaps an additive effect is in place as discussed in hypothesis two. Anger and hostility are observed often as a stress response in Vietnam veterans, holocaust survivors, Japanese atomic bomb survivors, Cambodian refugees, victims of violent crimes (Peterson, Prout, \& Schwartz; 1993), and in child abuse survivors (Green, 1993). According to Green (1993):

the loss of control over aggressive impulses is largely determined by the child's basic identification with violent parents, associated with the use of 
'identification with the aggressor' as a major defense against feeling of anxiety and helplessness. Aggressive behavior associated with the victimization of others also represents an attempt to achieve mastery by turning a passive humiliating experience into an active attempt to control a feared object. The impulsive, hyperaggressive behavior may be regarded as an intrusion or reenactment of the original traumatic event, which breaches the child's defenses. (p.580) Adolescents are forming their individual ego identity. The psychosocial task of changing into an adult can be disrupted by major trauma. The result is role confusion or identity disruption. There is confusion over the future, a sense that time is unmanageable or uncontrollable, fears of uncontrollable self-behaviors, self-consciousness, a sense of being "fixed" into a role, frustration in reaching goals, avoidance of intimate relationships, strong anxiety, a sense of alienation, and disruption of value formation (Peterson, Prout, \& Schwartz, 1993). Any of these factors alone could cause aggressive behavior, but for most juvenile offenders with PTSD, they have had multiple traumas, witnessed or were victims of violence, had family members or friends who were perpetrators, and other negative factors in their lives prior to being arrested.

The EPI also interprets seven common combinations of scores. Of these seven, two combinations appear to describe measurable portions of the PTSD subgroups in this 
study (Low Gregarious + High Dyscontrolled and High Timid + High Controlled).

\section{Low Gregarious + High Dyscontrolled Profile}

Twenty-two juvenile offenders fit this profile, $33 \%$ of the with-PTSD and $10 \%$ of the without-PTSD classification.

"A person with this combination seeks adventures and novelty through things rather than through people; that is, by doing dangerous things and taking risks. For example, such a person might enjoy car racing, mountain climbing, etc. This pattern suggests the possibility of an impaired identification mechanism (Plutchik \& Kellerman, 1983, p.9).

One-third of the juvenile offenders with PTSD in this study fall into this combination of personality traits. Risk taking and use of psychoactive drugs may be attempts to regulate their internal emotional states (Herman, 1992). This walk with danger may be an indicator that these juveniles are reliving their traumas through their behavior, similarly to what younger children have shown in repeated traumatic play with persistent reexperiencing of their trauma(s).

The high majority of those juveniles who fell into this category, also had extremely low scores on the Trustful dimension, and extremely high scores on the Distrustful and Aggressive dimensions. These juveniles were typically white, Hispanic or mixed 
raced/other. Reviewing the individual interviews from this special group, each of these juveniles had experienced multiple violent traumas (i.e., they had seen someone die, had a family member die, had been physically or sexually abused, had been shot at or had a gun pulled on them, had been a victim of kidnapping, or violent assault, or witnessed violent acts on top of other traumas). Basically, these youth could no longer trust their environment to be safe, or that they would be protected. They had been victims of multiple shocking events. They were exceptionally angry individuals who overtly expressed their anger, and they were stubborn, resentful, and sarcastic. They were overly critical, and prone to be rejecting of strange people and of society's ideals. Most people would perceive them as hostile.

A large majority of these youth stated that their friends were older or younger than themselves, and that they had very few friends their own age. Even though they scored low in the Gregarious dimension, a majority of them stated that they had not become less interested in seeing friends or being with people since they had the experiences they had related. This involvement with friends was a common comment from those juvenile offenders who self-disclosed they had been "jumped" or physically assaulted. They would "hang out" at a friend's house, or friends would join them. They would go out in public in groups only. It seems that friends not only provided comforting, but provided a degree of 
safety for them. This high involvement with friends is in contrast to PTSD symptomatology.

\section{High Timid + High Control Profile}

Eleven juvenile offenders fit this profile, $20 \%$ of the without PTSD and $5 \%$ of the with PTSD classification. "This combination represents a definite anxiety pattern with strong likelihood of phobic and obsessive-compulsive behavior" (Plutchik \& Kellerman, 1983, p.9). The last five combination scores described by Plutchik and Kellerman (1983) are discussed in Appendix $\mathrm{C}$ as they were less discriminating between the PTSD subgroups in this study.

\section{Conflict Profile}

Conflict between opposing dimensions was observed in thirty-seven percent of the juvenile offenders without PTSD and $29 \%$ with PTSD. According to Plutchik and Kellerman (1983):

If two opposite emotions are above their respective means, it indicates strong conflict in that particular bipolar dimension. If one dimension is above average, and its bipolar opposite is below average, it indicates little conflict in that bipolar dimension, provided that the high scores are on the following dimensions: gregarious, trustful, timid and controlled (p.9). 
Thirty-one juvenile offenders displayed conflict in their scores: 9 in dyscontrolled/controlled, 11 in timid/aggressive, 12 in depressed/gregarious, 2 in trustful/distrustful. Precisely one-half of the juvenile offenders in each conflict area fell into without-PTSD subgroup. This appears to indicate that there are strong internal personality struggles going on, unrelated to PTSD.

van der Kolk (1985) found that men who developed post-traumatic stress disorder after combat in Vietnam, were most likely adolescents while in combat. They had also formed a close identity with the "combat unit" and the men in it. This identity was disrupted when a buddy was killed.

This loss generally was followed by acts of revenge and subsequent feeling of a profound lack of control over their destiny. Adolescents use their peer group as an intermediary stage between dependency on their family and emotional maturity, and the army, particularly under battlefield conditions, maximizes the impact of peer group cohesion. For these younger men. the death of a friend was experienced as the dissolution of the once omnipotent group and as a narcissistic injury. The sharing and reliving of common experiences may facilitate entrance into the world of adult relationships, a process that was arrested by the trauma ( $\mathrm{p} .365)$. 
His observations of high group identity, narcissistic injury, and a need for revenge were similarly seen in juvenile offenders with PTSD. If juvenile offenders are substituted for adolescent veterans, and the violent street scene in large urban cities for the war zone, often filled with combat (gang) units, we may find a common factor: narcissistic wounds. Both group members contain adolescents. They often take revenge for members' deaths or even milder street assauits. Most juvenile offenders spoke of their anger, not fear, after being jumped or in a large street fight. This personal wound or injury to their self-esteem brings out the high level of anger and aggressive behaviors. Group therapy was recommended by van der Kolk as a way to re-create a peer group, where sharing and reliving of common experiences may facilitate entrance into adulthood that was halted by trauma.

Additional Findings Summary Results and Explanations for Findings.

Gang affiliation was not directly solicited. Numerous juvenile offenders disclosed friendship with gang members or membership in gangs. Furthermore, observations of tattoos on fingers, hands and arms were common. The juvenile offenders unspoken code of macho or tough person was present at the start of some interviews. When the term upset was substituted for scary after a negative response to a question (i.e., "Has a very scary thing happened to you?"), conversations that disclosed fear reaction were possible. As the 
youth described the event, the interviewer would then repeat "was this a scary thing to you" and would often receive the affirmation then.

This study contributes to the growing body of knowledge on children and post-traumatic stress. Juvenile offenders are a high impact group, who have a high occurrence of multiple traumas throughout their childhoods. High rates of aggression are found in most juvenile offenders in this study, but the highest scores were reached by the juvenile offender with PTSD. Personality traits associated with juvenile offenders withPTSD may be found in other PTSD groups, but specific research is necessary to confirm this.

In some ways, juvenile offenders are no different from thousands of other people who have been exposed to traumatic events. Some of them develop post-traumatic stress disorder and others don't. We do know that when a juvenile offenders have a past history with multiple traumas, PTSD is probable, and clinical analysis is warranted. Society can no longer ignore the youth who have been traumatized in their childhood. They need assistance in coping with their traumatic life experiences. Clinical studies have found that children exposed to trauma may have higher levels of aggression, and express behaviors that represent their anger (Farrington, 1989; Grossman, 1991; Kisner, Heston, Milsap, \& Pruitt, 1991). We cannot be sure if treatment will change aggressive behavior that 
translated to criminal acts, but therapy is helping others who have PTSD. It is time to develop ongoing group and individual therapies inside the juvenile detention facilities to treat these children with PTSD.

Juvenile homicide rates have made the United States the most violent country in the industrialized world (Richters, 1993). Community violence is exposing greater numbers of children to death, murder, and mayhem. Younger children are involved with carrying weapons and the violence that follows weapon carrying (Bell \& Jenkins, 1993). Whether the increase in juvenile homicide rates is due to youth participation in drug dealing or gangs members has not been established. However, a greater number of children are being exposed to violence and this violence is affecting them. (Bell \& Jenkins, 1993; Cooley, Turner, \& Beide, 1995; Osofsky, Wewers, Hann \& Fick, 1993; Richters, \& Martinez, 1993).

Researchers should be aware of a unique symptom change. Some individuals with PTSD may tend to be unsociable, unfriendly, unaffectionate, and introverted, representing symptoms of avoidance. Normal low scores in gregariousness would indicate a tendency to isolate and be withdrawn. Interestingly, a high portion of the juvenile offenders who scored low in the Gregarious dimension did not seem to isolate themselves from friends, even though 57\% met PTSD criteria, and 68\% scored in the high range on the Depressed 
dimension. Does a "Gang" support system impact this PTSD symptom change? Or is it unique to adolescence? Perhaps our research should have controlled for gang affiliation in the juvenile offenders' sample.

Those persons working with juvenile offenders, should become aware of the differences in symptoms for PTSD in children. Knowing about the youths' life experiences, combined with their symptomatic behaviors, should help with their referrals them for clinical help. Hopefully, the results of this study will help those who deal with this group to have a better understanding of the personality traits that may accompany the juvenile with- or without- PTSD.

\section{Limitations}

Results of this study may be compromised by the effect of being arrested and being in the detention center shortly before the interviews (both have potential traumatic effects). Generalizability is limited to juvenile offenders from large urban areas. Another limitation of this study is connected to the general question of a limited childhood memory for multiple traumas (Terrs, 1994). Some leeway was given when interviewing the youth about behavior changes that took place after trauma, when the child disclosed multiple traumas that may have impacted behaviors for as long as the child had had memories.

The statistical power of 70 on the overall MANOVA was just a little lower than 
the ideal power setting of .80 . A larger sample size may have improved the overall MANOVA results as well as delineated more personality traits.

There is no one standard instrument for PTSD testing. Many measures have been developed over the years, but few of them have been designed specifically for children. The Children's PTSD Inventory (Saigh, 1989) improved the sensitivity to child symptoms, as well as allowed for exploration of many possible memories of traumatic events. The PTSD Interview (Watson et al., 1991) used in Schrack (1994), was designed to be used with Vietnam veterans, and appeared to be unable to pick up the total PTSD juvenile offender group.

\section{Future direction}

In conclusion, it is recommended that future research on juvenile offender and PTSD should look closer at the role of aggression, both overt and passive; youth support systems (i.e., gang affiliation); and further goals of the youth. One interviewer received information that some gang members, affiliated with one ethnicity, considered their criminal activities as transient and only normal as youth activities. Time has come for PTSD treatments designed to intervene in the negative behaviors brought on by traumas and the rising level of violence in America. 


\section{References}

Aljazireh, L. (1993). Historical, environmental and behavioral correlates of sexual offending by male adolescents: A critical review. Behavioral Sciences and the Law 11 423-440.

Atlas, J. A., Di Scipio, W. J., Schwartz, R., \& Sessoms, L. (1991). Symptom correlates among adolescents showing posttraumatic stress disorder versus conduct disorder. Psychological Reports, 69, 920-922.

Bell, C. C., \& Jenkins, E. J. (1993). Community violence and children on Chicago's Southside. Psychiatry, 56, 46-54.

Biehler, R. F. \& Hudson, L. M. (1986). Developmental psychology: An introduction. (3rd ed.). Boston: Houghton Mifflin Company.

Brent, D. A., Perper, J. A., Moritz, G., Liotus, L., Richardson, D., Canobbio, R., Schweers, J., \& Roth, C. (1995). Posttraumatic stress disorder in peers of adolescent suicide victims: Predisposing factors and phenomenology. The Journal of the American Academy of Child Psychiatry, 34, 209-215.

Cooley, M. R. Turner, S. M., \& Beidel, D. C. (1995). Assessing community violence: The children's report of exposure to violence. The Journal of the American Academy of Child Psychiatry, 34, 201-208.

Deblinger, E., McLeer, S. V., Atkins, M. S., Ralphe, D., \& Foa, E. (1989).

Post-traumatic stress in sexually abused, physically abused, and nonabused children. Child Abuse \& Neglect, 13, 403-408.

Doyle, J. S., \& Bauer, S. K. (1989). Post-traumatic stress disorder in children: Its identification and treatment in a residential setting for emotionally disturbed youth. Journal of Traumatic Stress, $2,275-288$.

Eth, S. (1990). Post-traumatic stress disorder in childhood. In M. Hersen \& C. G. Last (Eds.), Handbook of child and adult psychopathology: A longitudinal perspective (pp. 261-274). New York: Pergamon Press. 
Eth, S., \& Pynoos, R. S. (1983). Children who witness the homicide of a parent. Presented at the 1983 annual meeting of the American Academy of Child Psychiatry.

Famularo, R, Kinscherff, R., \& Fenton, T. (1990). Symptom differences in acute and chronic presentation of childhood post-traumatic stress disorder. Child Abuse \& Neglect. 14, 439-444.

Farrington, D. P. (1989). Early predictors of adolescent aggression and adult violence. Violence and Victims, 4, 78-100.

Fitzpatrick, K. M., \& Boldizar, J. P. (1993). The prevalence of and consequences of exposure to violence among African-American youth. The Journal of the American Academy of Child Psychiatry, 32, 424-430.

Garbarino, J., Kostelny, K., \& Dubrow, N. (1991). What children can tell us about living in danger. American Psychologist, 46, 376-383.

Gidycz, C. A., \& Koss, M. P. (1989). The impact of adolescent sexual victimization: Standardized measures of anxiety, depression and behavioral deviancy. Violence and Victims, $4,139-149$

Green, A. (1993). Childhood sexual and physical abuse. In J. P. Wilson \& B. Raphael (Eds.). International handbook of traumatic stress syndromes. (pp. 577-592). New York: Plenum Press.

Grossman, W. I. (1991). Pain, aggression, fantasy, and concepts of sadomasochism. Psychoanalytic Quarterly, IX, 22-52.

Helzer, J. E., Robins, L. N., \& McEvoy, L. (1987). Post-traumatic stress disorder in the general population. The New England Journal of Medicine, 317, 1630-1634.

Herman, J. L. (1992). Trauma and recovery. New York: Basic Books.

Hill, E. G. (1995). Juvenile crime: outlook for California. Legislative Analyst's Office. 
Hubbard, J., Realmuto, G. M., Northwood, A. K., \& Masten, A. S. (1995). Comorbidity of psychiatric diagnoses with posttraumatic stress disorder in survivors of childhood trauma. The Journal of the American Academy of Child Psychiatry, 34,1167-1173.

Keppel, G., Saufley, W. H., \& Tokunaga, H. (1992). Introduction to design \& analysis: A student's handbook (2nd ed.). New York: W.H. Freeman and Company.

Kinzie, J. D., Sack, W. H., Angell, R. H., Manson, S., \& Rath, B. (1986). The psychiatric effects of massive trauma on Cambodian children: The children. The Journal of the American Academy of Child Psychiatry, 25, 370-376.

Kiser, L. J., Ackerman, B. J., Brown, E., Edwards, N. B., McColgan, E., Pugh, R., \& Pruitt, D. B. (1988). Post-traumatic stress disorder in young children: A reaction to purported sexual abuse. The Journal of the American Academy of Child and Adolescent Psychiatry, 27, 645-649.

Kiser, L. J., Heston, J., Millsop, P. A., \& Pruitt, D. B. (1991). Physical and sexual abuse in childhood: Relationship with post-traumatic stress disorder. Journal of American Academy of Child and Adolescent Psychiatry, 30, 776-783.

Krystal, H. (1993). Beyond the DSM-III-R: Therapeutic considerations in posttraumatic stress disorder. In J. P. Wilson \& B. Raphael (Eds.). International handbook of traumatic stress syndromes. (pp. 841-854).

Lorion, R. P., \& Saltzman, W. (1993). Children's exposure to community violence: Following a path from concern to research to action. Psychiatry, 56, 55-65.

Macksoud, M. S., Dyregrou, A., \& Raundalen, M. (1993). Traumatic war experiences and their effects on children. In J. P. Wilson \& B. Raphael (Eds.). International handbook of traumatic stress syndromes. (pp. 625-633).

Maiuro, R. D., \& Eberle, J. A. (1989). New developments in research on aggression: An international report. Violence and Victims, 4, 3-15. 
Martinez, P., \& Richters, J. E. (1993). The NIMH community violence project: II Children's distress symptoms associated with violence exposure. Psychiatry, 56, 22-35.

McCloskey, L. A., Southwick, K., Fernández-Esquer, M. E., \& Locke, C. (1995). The psychological effects of political and domestic violence on Central America and Mexican immigrant mothers and children. Journal of Community Psychology, 23. 95-116.

McLeer, S. V., Deblinger, E., Atkins, M. S., Foa, E. B., \& Ralphe, D. L. (1988). Post-traumatic stress disorder in sexually abused children. The Journal of American Academy of Child and Adolescent Psychiatry, 27, 650-654.

Muster, N. J. (1992). Treating the adolescent victim-turned-offender. Adolescence, 27 , $441-450$.

Olson, G. K. (1994). Counseling teenagers. Loveland: Group Publishing Inc.

Osofsky, J. D., Wewers, S., Hann, D. M., \& Fick, A. C. (1993). Chronic community violence: What is happening to our children? Psychiatry, 56, 36-45.

Peterson, K. C., Prout, M. F., \& Schwartz, R. A. (1993). Post-traumatic stress disorder: A clinician's guide. (3rd ed.). New York: Plenum Press.

Plutchik, R. (1962). The emotions: Facts, theories and a new model. New York: Random House.

Plutchik, R., \& Kellerman, H. (1983). Emotions profile index manual (2nd ed.). Los Angeles: Western Psychological Services.

Pynoos, R. S., \& Nader, K. (1989). Children's memory and proximity to violence. The Journal of American Academy of Child and Adolescent Psychiatry, 28, 236-241.

Richter, J. E. (1993). Community violence and children's development: Towards a research agenda for the 1990's. Psychiatry, 56, 3-6. 
Richter, J. E., \& Martinez, P. (1993). The NIMH community violence project: I Children as victims of and witnesses to violence. Psychiatry, 56, 7-21.

Riggs, P. D., Baker, S., Mikulich, S. K., Young, S. E., \& Crowley, T. J. (1995). Depression in substance-dependent delinquents. The Journal of American Academy of Child and Adolescent Psychiatry, 34, 764-771.

Rubinstein, M., Yeager, C., Goodstein, C., \& Lewis, D. (1993). Sexually assaultive male juveniles: A follow-up. American Journal of Psychiatry, 150, 262-265.

Saigh, P. A. (1989). The development and validation of the Children's Posttraumatic Stress Disorder Inventory. International Journal of Special Education, 4, 75-84.

Schrack, N. J. (1994). Frequency of post-traumatic stress disorder in juvenile offenders and level of aggression in identified PTSD juvenile offenders. Unpublished senior thesis, San Jose State University, San Jose, California. Poster session presented at the 1995 annual meeting of Western Psychological Association, Los Angeles, CA.

Silvern, L., \& Kaersvang, L. (1989). The traumatized children of violent marriages. Child Welfare, LXVIII, 421-436.

Spivak, H., Hausman, A. J., and Prothrow-Stith, D. (1989). Practitioner's forum: Public health and the primary prevention of adolescent violence-the violence prevention project. Violence and Victims, 4, 203-212.

Stallard, P., \& Law, F. (1993). Screening and psychological debriefing of adolescent survivors of life-threatening events. British Journal of Psychiatry, 163, 660-665.

SPSS for windows 6.0 [Computer software]. (1993). Chicago, Illinois.

Steiner, H., \& Feldman, S. S. (1995). Two approaches to the measurement of adaptive style: Comparison of normal, psychosomatically ill, and delinquent adolescents. The Journal of American Academy of Child and Adolescent Psychiatry, 34, $180-190$.

Terr, L. C. (1991). Childhood traumas: An outline and overview. American Journal of Psychiatry, 148, 10-20. 
van der Kolk, B. A. (1985). Adolescent vulnerability to posttraumatic stress disorder. Psychiatry, 48, 365-370.

Watson, C. G., Juba, M. P., Manifold, V., Kucala, T., \& Anderson, P. E. (1991). The PTSD Interview: Rationale, description, reliability, and concurrent validity of DSM-III-based technique. Journal of Clinical Psychology, 47, 179-188.

Weisman, G. K. (1993). Adolescent PTSD and developmental consequences of crack dealing. American Journal of Orthopsychiatry, 63, 553-561.

Widom, C.S. (1991). The role of placement experiences in mediating the criminal consequences of early childhood victimization. American Journal of Orthopsychiatry, 61, 195-209. 
Emotional Profiles of PTSD 54

\section{APPENDICES}




\section{APPENDIX A}

\section{Juvenile Offender Research Project Background Questionnaire}

1. Identification No. Age Sex: Male Female

2. Number of children residing in same residence with you.

3. Number of adults sharing residence with you.

4. At what age did you first appear before the Juvenile Court?

5. How many times have you been appeared before the Juvenile Court?

6. What is your primary language?

7. Ethnicity: Circle one: Native American Asian American/Asian AfricanAmerican/Black White Mexican American/Hispanic/Latino Other:

8. Have you ever experienced any of the following?
(A) Major Accident Circle one: Yes or No If yes, how many? Car Plane Train Bus Boat Sports

(B) Have you ever seen a person die?

Circle one: Yes or No

(C) Have you ever been physically or sexually abused? Circle one: Yes or No

(D) Have you ever been a victim of terrorism. kidnapping or violent assault?

Circle one: Yes or No

(E) Have you ever experienced a natural disaster? If Yes, how many and what year?

Hurricane
Residential Fire
Tidal Wave
Tornado

\section{Major Earthquake} Other Building Fire Flood Loss of Home

(D) Have you ever been diagnosed with any of the following?

Make a check mark by any diagnosis $x$

Anxiety Disorder

Benign Tumors

BiPolar Disorder

Cancer

Heart Attack

Major Depression

Migraine Headaches
Obsessive-Compulsive Disorder Panic Disorder Personality Disorder (any) Post-traumatic Stress Disorder Schizophrenia Stroke Tuberculosis 


\section{Appendix B \\ Children's PTSD Inventory (CPTSD-I) 1 \\ DSM-IV Version}

Philip A. Saigh , Ph.D.

The Graduate School and University center

The City University of New York

\section{Examinee}

Sex: Male

Female

ID number

Date of Examined

Date of Birth

Age

Examiner Telephone Contact

\section{A 1. EXPOSURE}

SAY: " Sometimes very scary things can happen to young people. Some of them have been badly beaten or taken away from their parents. Others have been hurt in accidents or fires. Sometimes people have done bad things to the private parts of young people. Children and teen-agers have also been hurt in wars. Others have seen people who were badly injured or killed in their homes or neighborhoods."

1a. SAY: "Has a very scary thing happened to you?"
CHECK:
Yes:
No:

If "No" was indicated and the Examiner has no reason to believe that the Examince was exposed to a significant stressor. TURN to page 3 and Present Question 2a.

1Copyright 1994 by Philip A. Saigh. Ph.D. All rights reserved No part of this booklet may be reproduced or transmitted by any means or form without the written permission of the author.

If "Yes" was indicated. Say: "Tell me about it."

Record the Examinee's actual statement. 
NOTE: If the Examinee previously informed the Examiner about an incident wherein he or she was exposed to an event that involved actual or potential serious injury, death. or a viable threat to the bodily integrity of the Examinee, and if an equivocal or non-highly stressful experience is presented. SAY: "A while ago you told me. . (briefly describe the incident). Can you tell me about this again?" If the Examinee does so, RECORD the actual statement in the space that is provided. If the Examiner was advised by a referent or an objective source of information that the Examinee was exposed to an extreme form of stress and the Examinee fails to acknowledge this. SAY: "Mr./ Ms./ Dr./ Your records (name the referent, informant, or specific agency record) told me/indicate. . .(briefly describe the event). Can you tell me about this?" If the Examinee does so. RECORD the actual statement in the space that is provided. Should the Examinee continue to deny exposure to a reported event. DISCONTINUE the evaluation and engage the Examinee in a non-threatening conversation that is intended to facilitate rapport. If rapport is established. the Examiner should attempt to discuss the reported incident with the Examinee. If these efforts are successful, RE ADMINISTER item 1a. Should the Examinee refuse to acknowledge the incident. TERMINATE the evaluation and RECORD NO DIAGNOSIS ON PAGE 19. Otherwise. CONTINUE the evaluation.

SAY: "When did this happen?"

NOTE: Young children may be unable to accurately gauge time. If this occurs. SECURE an estimate from the referent or obtain a reference from an objective source of information after the interview.

RECORD: Year__ Month

DETERMINE if the Examinee experienced or was confronted by an event that involved actual or potential serious injury. death. or a threat to the bodily integrity of the youth or other people.
CHECK:
Yes:
No:

1b. SAY: "Did another very scary thing happen to you?"

CHECK: Yes: ___ No:

If "No" was indicated and the Examiner has no reason to believe that the Examinee experienced another significant stressor. PRESENT Question 2a.

If "Yes" was indicated. Say: "Tell me about it."

Record the Examinee's actual statement 
SAY: "When did this happen?"

RECORD: Year__ Month

NOTE: If it is apparent that the Examinee is unable to accurately gauge time. SECURE an estimate from the referent or obtain a reference from an objective source of information after the interview.

DETERMINE if the Examinee experienced or was confronted by an event that involved actual or potential serious injury, death. or a threat to the bodily integrity of the youth or other people.

CHECK: Yes:___ No:

2a. SAY: "Have you seen a very scary thing happen to someone else?"

CHECK: Yes:___ No:

If "No" was indicated and the Examiner has no reason to believe that the Examinee experienced another significant stressor. TURN to page 6 and SCORE Section AI.

If "Yes" was indicated Say: "Tell me about it."

Record the Examinee's actual statement.

NOTE: If the Examinee previously informed the Examiner about an incident wherein he or she was exposed to an event that involved actual or potential serious injury. death. or a viable threat to the bodily integrity of the Examinee. and if an equivocal or non-highly stressful experience is presented. SAY: "A while ago you told me. . (briefly describe the incident). Can you tell me about this again?" If the Examinee does so. RECORD the actual statement in the space that is provided. If the Examiner was advised by a referent or an objective source of information that the Examinee observed an extreme form of stress and the Examinee fails to acknowledge this. SAY: "Mr./ Ms./ Dr./ Your records (name the referent. informant. or specific agency record) told me/indicate. . (briefly describe the event). Can you tell me about this?" If the Examinee does so. RECORD the actual statement in the space that is provided. Should the Examinee continue to deny exposure to a reported event. DISCONTINUE the evaluation and 
engage the Examinee in a non-threatening conversation that is intended to facilitate rapport. If rapport is established. the Examiner should attempt to discuss the reported incident with the Examinee. If these efforts are successful, RE ADMINISTER item 2a. Should the Examinee refuse to acknowledge the incident, TERMINATE the evaluation and RECORD NO DIAGNOSIS ON PAGE 19. Otherwise. CONTINUE the evaluation.

SAY: "When did this happen?"

RECORD: Year

NOTE: If it is apparent that the Examinee is unable to accurately gauge time. SECURE an estimate from the referent or obtain a reference from an objective source of information after the interview.

DETERMINE if the Examinee observed an event that involved actual or potential serious injury. death. or a threat to the bodily integrity of the youth or other people.
CHECK:
Yes:
No:

2b. SAY: "Did you seen another very scary thing happen to someone else?"
CHECK:
Yes:
No:

If "No" was indicated and the Examiner has no reason to believe that the Examinee experienced another significant stressor. TURN to page 6 and SCORE Section Al.

If "Yes" was indicated. Say: "Tell me about it."

Record the Examinee's actual statement.

SAY: "When did this happen?"

NOTE: If it is apparent that the Examinee is unable to accurately gauge time. SECURE an estimate from the referent or obtain a reference from an objective source of information after the interview.
RECORD:
Year
Month

DETERMINE if the Examinee observed an event that involved actual or potential serious injury. death. or a threat to the bodily integrity of the youth or other people. 
CHECK: Yes:

No:

\section{A 1. EXPOSURE SCORING}

1. If the Examinee said "No" to Questions la. 1b. 2a, and 2b, RECORD a 0 in the scoring box. TURN to page 19. CHECK PTSD NEGATTVE, and TERMINATE the evaluation.

2. If the Examinee's verbatim statement did not involve exposure to a significant stress. RECORD a 0 in the scoring box. TURN to page 19. CHECK PTSD NEGATIVE. and TERMINATE the evaluation.

3. If the Examinee said "Yes" to Questions la. lb. 2a. and 2b. RECORD a 1 in the scoring box. and CONTINUE the evaluation.

\section{A 1. EXPOSURE SCORE *}

\section{A 2. SITUATIONAL REACTIVTTY}

1. SAY: "were you very scared when this happened? "
CHECK:
Yes
No

2. SAY: "Did you feel very excited when this happened? "

CHECK: Yes___ No

3. SAY: "Did you have a hard time understanding what was happening? "
CHECK:
Yes
No

4. SAY: "Did you feel that you could not do anything to stop this from happening?"

CHECK: Yes

No

\section{A 2. SITUATIONAL REACTIVITY SCORING}

1. If the Examinee said "No" to Questions 1. 2, 3. and 4. RECORD a 0 in the scoring box. TURN to page 19. CHECK PTSD NEGATIVE, and TERMINATE the evaluation.

2. If the Examinee said "Yes" to Questions 1. 2. 3. and 4. RECORD a 1 in the scoring box. and CONTINUE the evaluation.

\section{A 2. SITUATIONAL REACTIVITY*}

\section{B. REEXPERIENCING}

1a. SAY: "Are you having a lot of upsetting thoughts about what happened? "
CHECK:
Yes
No

If "Yes" was indicated SAY: "Have these thoughts been bothering you for a month or more? "

CHECK:

Yes

No 
1b. SAY: "Do pictures about what happened to you keep popping into your head? "

If "Yes" was indicated SAY: "Have these thoughts been bothering you for a month or more?"

CHECK:

Yes

No

1c. SAY: Have you been playing games or drawing pictures about what happened? " CHECK:

Yes No

If "Yes" was indicated. SAY: "Have these thoughts been bothering you for a month or more? " CHECK:

Yes No

2a. SAY: "Are you having a lot of bad dreams about what happened? "
CHECK:
Yes
No

If "Yes" was indicated. SAY: "Have these thoughts been bothering you for a month or more? "
CHECK:
Yes
No

2b. SAY: "Have you been having bad dreams that you are not able to remember after you wake up? "
CHECK:
Yes
No

If "Yes" was indicated SAY: "Have you been baving these dreams for a month or more"?

CHECK: Yes

No

3. SAY: "Do you sometimes feel as if your bad experiences is happening all over again?"

CHECK: Yes No

If "Yes" was indicated. SAY: "Have you been having these feelings for a month or more"?

CHECK: Yes__ No

4. SAY: "Do you become very upset if you see or think about people. places. or things that remind you about what happened? "

CHECK:

Yes

No

If "Yes" was indicated SAY: "Have you been feeling this way for a month or more"?

CHECK: Yes___ No

5a. SAY: "If you see or think about people, places. or things that remind you about what happened do your hands feel sweaty"?

CHECK: Yes_ No

If "Yes" was indicated. SAY: "Has this been happening for a month or more?"

CHECK: Yes__ No

5b. SAY: "If you see or think about people. places. or things that remind you about what happened. does your heart beat more quickly? "

CHECK: Yes___ No

If "Yes" was indicated SAY: "Has this been happening for a month or more? "

CHECK: Yes__ No___ 
5c. SAY: "If you see or think about people. places. or things that remind you about what happened. do you have trouble breathing? "
CHECK:
Yes
No

If "Yes" was indicated SAY: "Has this been happening for a month or more? "
CHECK:
Yes
No

5d. SAY: "If you see or think about people. places, or things that remind you about what happened. do you get a bad feeling in your stomach? "

CHECK: Yes__ No

If "Yes" was indicated SAY: "Has this been happening for a month or more? "

CHECK:

Yes

No

\section{B. RE-EXPERIENCING SCORING}

NOTE: Single or multiple "Yes" responses to items 1a-1c, 2a or $2 b$, and 5a-5d are to be scored as a single affirmative answer for the numerical item.

1. If the Examinee said "No" to Questions 1-5. RECORD a 0 in the scoring box. TURN to page 19. CHECK PTSD NEGATIVE. and TERMINATE the evaluation.

2. If the Examinee said "Yes" to $l$ or more Questions. and symptoms were not reported for a more than a month (in each instance). RECORD a 0 in the scoring box. TURN to page 19. CHECK PTSD NEGATIVE. and TERMINATE the evaluation.

3. If the Examinee said "Yes" to Questions I or more of the Questions and symptoms were reported for more than a month (in each instance). RECORD a 1 in the scoring box. and CONTINUE the evaluation.

\section{B. REEXPERIENCING SCORE*}

\section{AVOIDANCE \& NUMBING}

1A. SAY: "Have you been trying not to think about what happened? "
CHECK:
Yes
No

If "Yes" was indicated. SAY: "Have you been doing this for a month or more? "

CHECK: Yes__ No

1b. SAY: "Have you been trying not to have feeling about what happened? "
CHECK:
Yes
No

If "Yes" was indicated. SAY: "Have you been doing this for a month or more?"

CHECK:

Yes

No

1c. SAY: "Have you been trying not to talk about what happened? "

CHECK:

Yes

No 
if "Yes" was indicated. SAY: "Have you been doing this for a month or more?"
CHECK:
Yes
No

2a. SAY: "Have you been trying to stop doing things that remind you about what happened ?"
CHECK:
Yes
No

If "Yes" was indicated. SAY: "Have you been doing this for a month or more?"
CHECK:
Yes
No

2b. SAY: "Have you been trying to stay away from places that remind you about what happened? "
CHECK:
Yes
No

If "Yes" was indicated SAY: "Have you been doing this for a month or more?".
CHECK:
Yes
No

2c. SAY: "Have you been trying to stay away from places things that remind you about what happened?"
CHECK:
Yes
No

If "Yes" was indicated SAY: "Have you been doing this for a month or more?".

CHECK: Yes_ No

3. SAY: "Are there parts of the experience that you have trouble remembering even when you try ?

n
CHECK:
Yes
No

If "Yes" was indicated. SAY: "Have you been unable to remember for a month or more? "

CHECK: Yes__ No

4a. SAY: "Have you become less interested in seeing friends or being with people. since you had the experience that you told me about? "
CHECK:
Yes
No

If "Yes" was indicated. SAY: "Have you been feeling this way for a month or more?"

CHECK: Yes_ No

4b. SAY: "Have you become less interested in doing things that you used to enjoy since you had the experience that you told me about?"
CHECK:
Yes
No

If "Yes" was indicated SAY: "Have you been feeling this way for a month or more?"

CHECK: Yes__ No

5a. SAY: "Have you been feeling that you are different from your classmates since this happened? " CHECK: Yes__ No

If "Yes" was indicated. SAY: "Have you been feeling this way for a month or more?"

CHECK: Yes__ No

5b. SAY: "Have you been feeling that you are not really involved with kids your age?" 
CHECK: Yes No

If "Yes" was indicated. SAY: "Have you been feeling this way for a month or more? "

CHECK: Yes_ No

6. SAY: "Has it become difficult for you to feel things or to show other people how you really feel since you had the experience that you told me about? "

CHECK: Yes_ No

If "Yes" was indicated, SAY: "Have you been feeling this way for a month or more? "

CHECK: Yes___ No

7a. SAY: "Since this happened, have you changed your mind about what you want to do in the future?" For example. have you changed your mind about what you want to do when you get older? "

CHECK: Yes No

If "Yes" was indicated. SAY: "Have you been feeling this way for a month or more? "

CHECK: Yes_ No

7b. Since this happened, have you changed your mind about getting married in the future?"

CHECK: Yes No

If "Yes" was indicated SAY: "Have you been feeling this way for a month or more? "

CHECK: Yes__ No

7c. Since this happened. have you changed your mind about becoming a parent in the future? "

CHECK: Yes_ No

If "Yes" was indicated SAY: "Have you been feeling this way for a month or more? "

CHECK: Yes__ No

7d. Since this happened, have you changed your mind about your chances of having a long life? "

CHECK: Yes__ No

If "Yes" was indicated SAY: "Have you been feeling this way for a month or more? "

CHECK:

Yes

No

\section{AVOIDANCE \& NUMBING SCORING}

NOTE: Single or multiple "Yes" responses to items $1 \mathrm{a}-1 \mathrm{c}, 2 \mathrm{a}-2 \mathrm{c}, \mathrm{fa}$ or $4 \mathrm{~b}, 5 \mathrm{a}$ or $5 \mathrm{~b}$ and $7 \mathrm{a}-7 \mathrm{~d}$ are to be scored as a single affirmative answer for the numerical item.

1. If the Examinee said "No" to 5 or more Questions. RECORD a 0 in the scoring box. TURN to page 19. CHECK PTSD NEGATIVE. and TERMINATE the evaluation.

2. If the Examinee said "Yes" to 3 or more Questions. and symptoms were not reported for a more than a month (in each instance). RECORD a 0 in the scoring box. TURN to page 19. CHECK PTSD

NEGATIVE. and TERMINATE the evaluation.

3. If the Examinee said "Yes" to 3 or more of the Questions and symptoms were reported for more than a 
month (in each instance), RECORD a $I$ in the scoring box. and CONTINUE the evaluation.

C. AVOIDANCE \& NUMBING SCORE

\section{INCREASED AROUSAL}

1. SAY: "Since this happened, has it been difficult to go to sleep or stay asleep at night? "
CRECK:
Yes
No
If "Yes" was indicated SAY: "Have you been feeling this way for a month or more?".
CHECK: Yes__ No

22. SAY: "Since this happened have you been getting very angry?"
CHECK:
Yes
No
If "Yes" was indicated SAY: "Have you been having these feelings for a month or more? "

CHECK: Yes__ No

2b. SAY: "Since this happened. have you been yelling at people?"
CHECK:
Yes
No

If "Yes" was indicated SAY: "Have you been doing this way for a month or more?"

CHECK: Yes_ No

2c. SAY: "Since this happened. have you been getting into fights? "
CHECK:
Yes
No

If "Yes" was indicated SAY: "Have you been doing this way for a month or more?"

CHECK: Yes___ No_

3. SAY: "Since this happened has it been difficult to pay attention in class or to carefully listen to what people are saying? "
CHECK:
Yes
No

If "Yes" was indicated. SAY: "Have you been having these problems for a month or more? "

CHECK: Yes__ No

4. SAY: "Since this happened. have you become very careful or watchful? "

CHECK: Yes__ No

If "Yes" was indicated SAY: "Have you been doing this for a month or more? "

CHECK: Yes_ No

5. SAY: "Since this happened do loud noises or sudden sounds make you jump or jerk? "
CHECK:
Yes
No
"Yes" was indicated SAY: "Have loud noises been bothering you for a month or more? "

CHECK:

Yes

No

D. INCREASED AROUSAL SCORE 
NOTE: Single or multiple "Yes" responses to items 2a-2c are to be scored as a single affirmative answer for the numerical item.

1. If the Examinee said "No" to 4 or more Questions. RECORD a 0 in the scoring box. TURN to page 19. CHECK PTSD NEGATIVE. and TERMINATE the evaluation.

2. If the Examinee said "Yes" to 2 or more Questions. and symptoms were not reported for a more than a month (in each instance), RECORD a 0 in the scoring box. TURN to page 19. CHECK PTSD

NEGATIVE. and TERMINATE the evaluation.

3. If the Examinee said "Yes" to 2 or more of the Questions and symptoms were reported for more than a month (in each instance). RECORD a 1 in the scoring box and CONTINUE the evaluation.

D. INCREASED AROUSAL SCORE

\section{E. SIGNIFICANT DISTRESS}

1. SAY: "Have you been more upset than you used to be before this happened?" CHECK: Yes No

If "Yes" was indicated. SAY: "Tell me about the way you have been feeling".

Record the Examinee's actual statement

2. SAY: "Have you been having problems with your classmates or other children since you bad e.perience occurred? "

CHECK: Yes_ No

If "Yes" was indicated. SAY: "Tell me about these problems".

Record the Examinee's actual statement 
3. SAY: "Have your grades in school gotten worse since this happened? "

CHECK: Yes_ No

If "Yes" was indicated. SAY: "Tell me about these problems".

Record the Examinee's actual statement.

4. SAY: "Have you been having more problems with your parents/ or the people that you live with (Select one) since this happened? "

CHECK:

Yes

No

If "Yes" was indicated SAY: "Tell me about these problems".

Record the Examinee's actual statement.

5. SAY: "Have you been having more problems with your teachers since this happened?"
CHECK:
Yes
No

If "Yes" was indicated. SAY: "Tell me about the way you have been feeling".

Record the Examinee's actual statement. 
1. If the Examinee said "No" to $f$ or more Questions, RECORD a 0 in the scoring box. TURN to page 19. CHECK PTSD NEGATTVE, and TERMINATE the evaluation.

2. If the Examinee said "Yes" to 2 or more Questions. DETERMINE if the Examinee is experiencing significant distress and or an impairment in social. occupational (i.e.. scholastic achievement). or other areas of functioning as indicated by the verbatim responses to each Question. Examiners may also consider external sources of evidence (e.g.. an academic transcript of record. actual behavioral observations. or significantly elevated scores on nationally standardized teacher administered behavioral rating forms) in making the determination.

CHECK: Yes_ No

3. If the Examinee said "Yes" to 2 or more Questions and is experiencing significant distress and a functional impairment. RECORD a 1 in the scoring box and CONTINUE.

\section{E. SIGNIFICANT DISTRESS SCORE $\square$}

\section{DSM-IV AXIS I DIAGNOSES}

1. SUM the scores that appear in scoring boxes A 1. A 2. and boxes B-E.

2. RECORD the sum in the Total Score box.

TOTAL SCORE

3. If the Total Score is less than 6. TURN to page 19 and CHECK PTSD NEGATIVE.

4. If the Total Score is 6. SAY: Have you been having these problems for less than three months?"

$$
\text { CHECK: Yes_ No }
$$

NOTE: If the Examinee is certain. SAY: "When did these problems begin?". Should the Examinee present a vague or equivocal answer. SECURE an estimate from the referent or obtain a reference from an objective source of information after the interview.

5. If the Total Score is 6 and if the Examinee said "No" in response Question 4. SAY: "Have you been having these problems for more than three months?
CHECK:
Yes.
No

NOTE: If the Examinee presents a vague or equivocal answer. SECURE an estimate from the referent or obtain a reference from an objective source of information after the interview.

6. If the Examinee said "Yes" to Question 4 or 5. SAY: "Did these problems begin at least six months after your bad experience occurred?"
CHECK:
Yes
No

7. If the Examinee said "Yes" to Question 4. TURN to page 19 and CHECK ACUTE PTSD. 
8. If the Examinee said "Yes" to Question 5. TURN to page 19 and CHECK CHRONIC PTSD.

9. If the Examinee said "Yes" to Question 6. TURN to page 19 and CHECK DELAYED ONSET PTSD.

10. CHECK ( $P$ ) one of the following:

PTSD NEGATIVE
ACUTE PTSD
CHRONIC PTSD
DELAYED ONSET PTSD
NO DIAGNOSIS

Notes

? This description is reserved for instances wherein the Examinee fails to acknowledge documented evidence that he or she experienced saw. or was confronted by an event that involved actual or potential serious injury. death or a threat to the bodily integrity of the youth or other people. 


\section{Appendix C \\ The Emotions Profile Index}

Rober Plutchik. Ph.D. and Henry Kellerman. Ph.D.

Rousened or

WpS

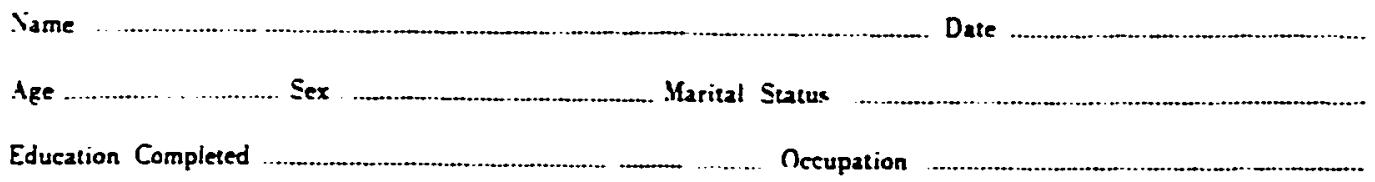

\section{Instructions}

On the inside of this booklet you will find pairs of words which describe people: words such as fdrenturous. Affectionate and Cautious. From each pair, circle the word that describes you best.

For example: If you believe you are more .tdrenurous than Impulsice. you would indicate this in the following way:

\section{Adventurous}

Impulsive

Similarly, if you believe you are more Cautious than . Affectionate. you would indicate this in the following way:

\section{Affectionate}

Cautious

Sometimes it may be difficult to decide which word in a pair fits you better but try to make the choice even if the difference is slight. Definitions of all the words used are provided. It is suggested that you look at them before beginning.

There is no time limit. 
Appendix $\mathrm{C}$ Continued
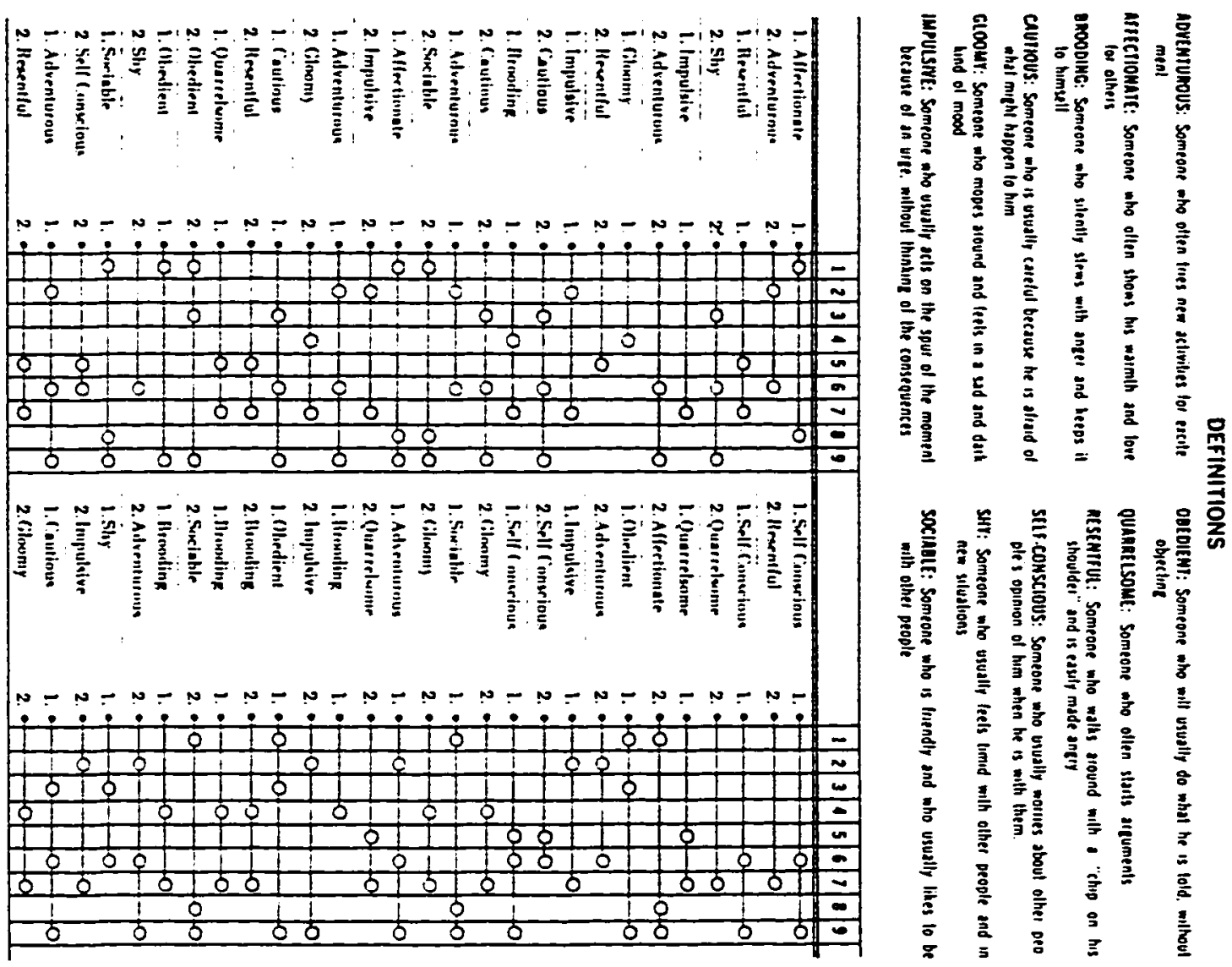

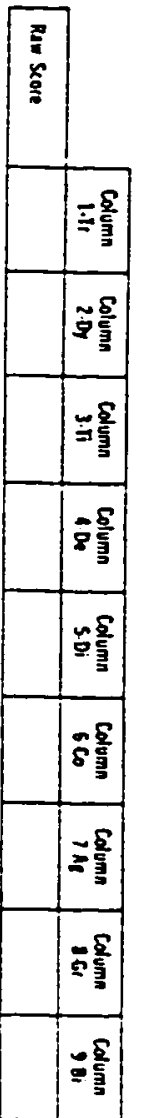

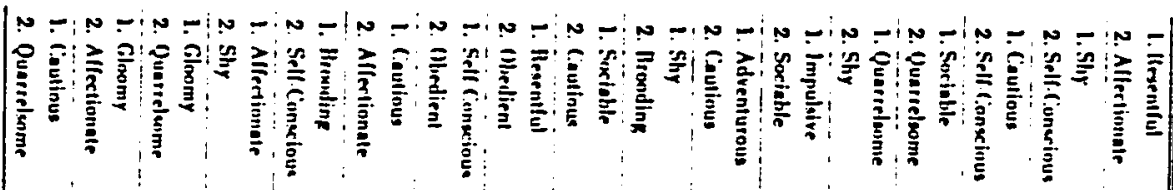

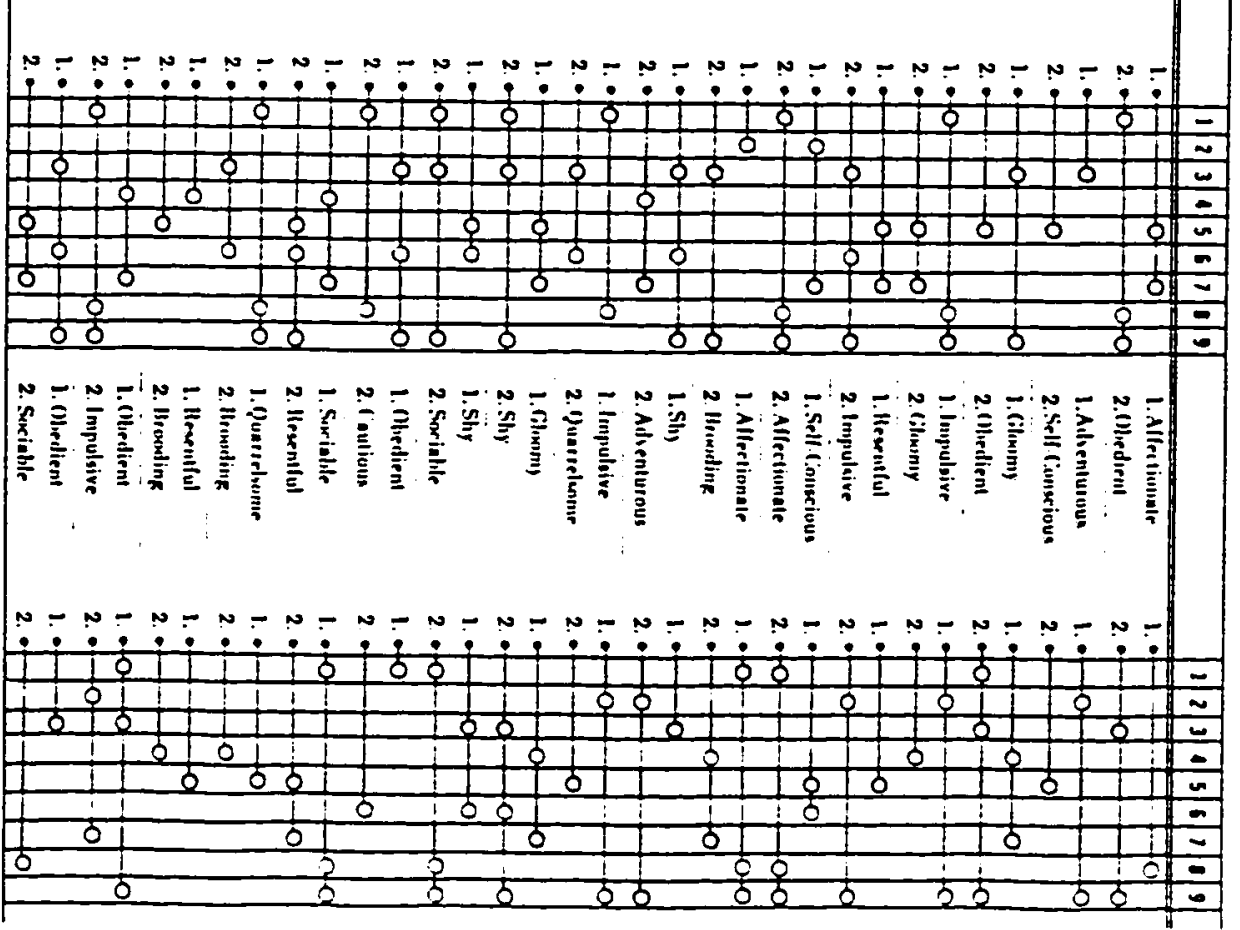




\section{Appendix C Continued}

\section{PROFILE SHEET}

Robert Plutchik. Ph.D. and Henry Kellerman. Ph.D.

WpS

\begin{tabular}{|l|}
\hline Name \\
\hline Oate \\
\hline Age Sex \\
\hline Marital Status \\
\hline Education Completed \\
\hline Occupation \\
\hline Comments \\
\hline \\
\hline
\end{tabular}

\begin{tabular}{|l|l|l|}
\hline \multicolumn{1}{|c|}{$\begin{array}{c}\text { Emotion } \\
\text { Dimensions }\end{array}$} & $\begin{array}{c}\text { Raw } \\
\text { Score }\end{array}$ & Percentile \\
\hline 1-Trustful & & \\
\hline 2-Dyscontrolled & & \\
\hline 3-Timid & & \\
\hline 4-Depressed & & \\
\hline 5-Distrustiul & & \\
\hline 6-Controlled & & \\
\hline 7-Aggressive & & \\
\hline 8-Gregarious & & \\
\hline 9-Bias & & \\
\hline
\end{tabular}

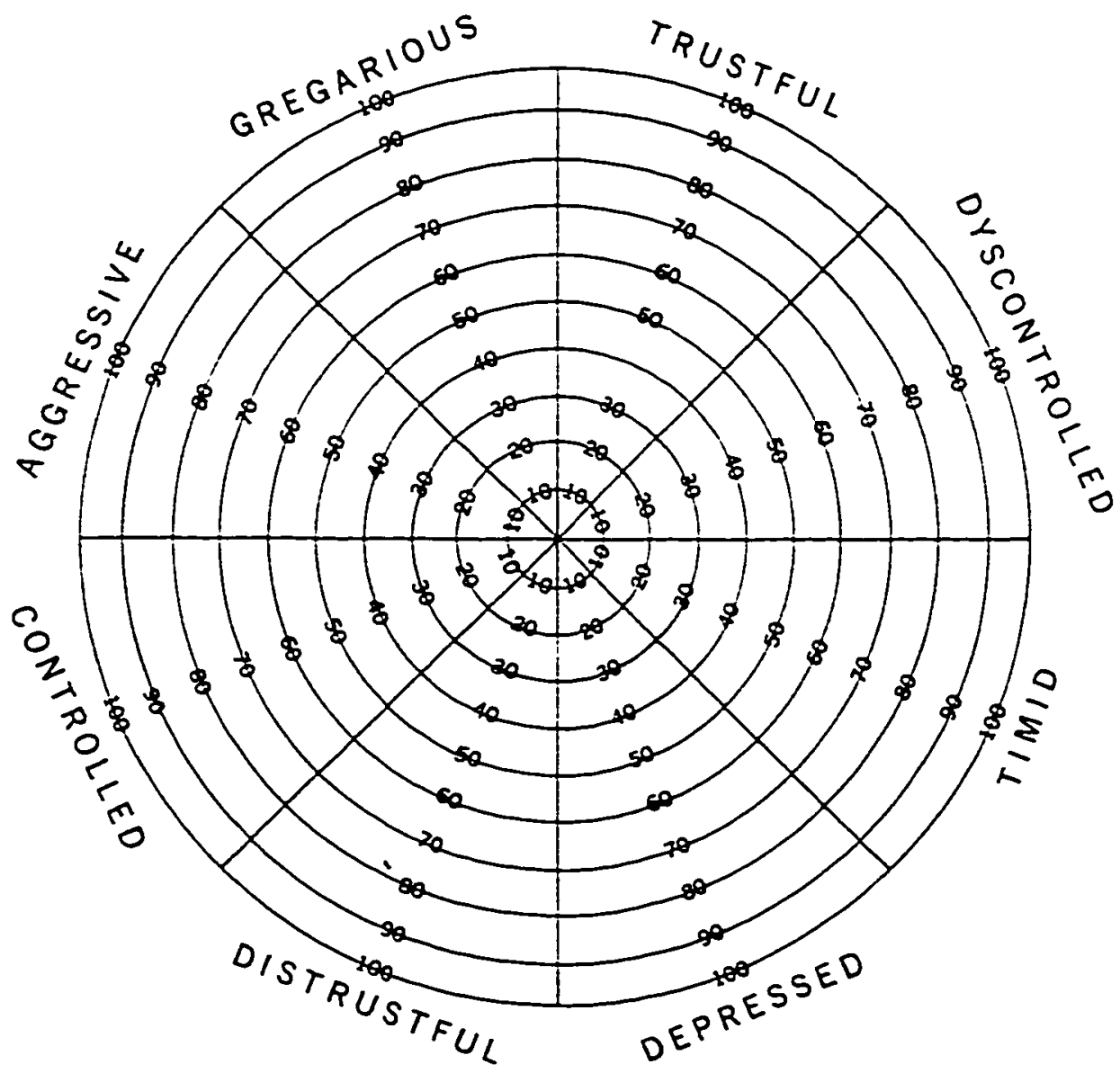

Copright (O 1974 by WESTERN PSYCHOLOGICAL SERVICES 


\section{Appendix C Continued}

The following descriptions pertain to the personality patterns of certain combinations of scores. The five combinations presented here are only a few of the more common combinations that are found. The descriptions are based upon the trait combinations (dyads) described more fully in Plutchik (1962).

\section{High Gregarious + High Timid.}

Four juvenile offenders fit this profile. All had a without PTSD classification (10\%). "This combination implies a strong conscience and a tendency to feel guilt rather easily. This implies a responsible, cautious person who has strong needs for social approval (Plutchik \& Kellerman, 1983, p.9).

\section{High Gregarious + Low Timid.}

Fourteen juvenile offenders fit this profile, $13 \%$ of the with PTSD and $17 \%$ of the without PTSD classification. "This combination implies a person who likes to be with people but who has a lack of conscience. He is not too responsible. There is also a possibility of psychopathic tendencies (Plutchik \& Kellerman, 1983, p.9).

\section{High Gregarious + High Dyscontrolled.}

Ten juvenile offenders fit this profile, $7 \%$ of the with PTSD and $15 \%$ of the without PTSD classification. "A person with this combination likes people and likes adventures. He likes to meet new people and enjoys having many friends and contacts. 
His socializing has an impulsive quality and may be insensitive (Plutchik \& Kellerman, 1983, p.9).

\section{High Gregarious + Low Trustful.}

Four juvenile offenders fit this profile, $5 \%$ with PTSD and $2 \%$ without PTSD classification. "This person likes to be with people but he is somewhat distrustful. He is a good socializer but does not take people at face value. He tends to be suspicious of people's motives" (Plutchik \& Kellerman, 1983, p.9).

High Trustful + Low Timid.

Eight juvenile offenders fit this profile, $7 \%$ of the with PTSD and 10\% of the without PTSD classification. "This person tends to exercise poor judgment and does risky things" (Plutchik \& Kellerman, 1983, p.9).

Interpretation of Emotional Profiles (EPI manual pgs 8-9)

\section{Gregarious Dimension (Reproduction)}

High Score: This person tends to be sociable, friendly, affectionate and somewhat extroverted. He enjoys being with people and likes to have warm, friendly contacts.

Low Score: This person tends to be unsociable, unfriendly, unaffectionate and introverted. He tends to be isolated and withdrawn.

\section{Trustful Dimension (Incorporation)}

High Score: This person tends to be accepting, trustful, obedient and gullible. He tends to take things at their face value. He would probably be 
described as a dependent person, or one who is suggestible.

Low Score: This person tends to be unaccepting, distrustful, disobedient and not very gullible. He does not take things at face value.

\section{Dyscontrolled Dimension (Orientation)}

High Score: This person tends to be impulsive. He likes to try new things and have new experiences. He likes surprises. He might also be described as adventurous or curious.

Low Score: This person tends to be unadventurous. He is reluctant to try new things or have new experiences. He is not impulsive and tends to withdraw from social contacts.

\section{Timid Dimension (Protection)}

High Score: This person tends to be cautious, careful and anxious. He worries about getting into trouble. He also worries about what people think of him and say about him.

Low Score: This person is less cautious and fearful than the average person. He tends to take risks and can easily get into trouble. He will do things that are dangerous and not in his own best interests. Extremely low scores may indicate impaired reality testing.

\section{Depressed Dimension (Reintegration)}

High Score: This person is pressed, sad and gloomy. He is dissatisfied with aspects of his life. He feels deprived and is probably pessimistic. Extremely high scores may be associated with suicidal tendencies.

Low Score: This person is satisfied with his style of life. Extremely low scores may reflect the operation of strong denial. 


\section{Distrustful Dimension (Rejection)}

High Score: This person tends to be stubborm, resentful and sarcastic. He is overly critical and tends to be rejecting of people and of ideas. He is most likely perceived by others as a hostile person. Another description of him might be "passive-aggressive," or guarded.

Low Score: This person tends to be uncritical and not rejecting.

\section{Control Dimension (Exploration)}

High Score: This person wants to know his environment and wants to learn to deal with it. He has a tendency to organize his life and put things in their proper pigeon holes. He has a need for order and likes being well organized. He exhibits a good deal of self-control. He would be perceived by others as compulsive, meticulous or well organized.

Low Score: This person tends to live his life on a day-to-day basis. He does not plan for the future. He tends to be disorganized in his thinking and in his activities. He has very little need for orderliness. He tends to have little self-control.

\section{Aggressive Dimension (Destruction)}

High Score: This person tends to be quarrelsome and aggressive. He tends to say whatever is on his mind. He has a lot of anger and expresses it overtly. He tends to blow off steam with people around. People might describe him as rebellious.

Low Score: This person is unaggressive and not quarrelsome. He has very little anger and is reluctant to express it overtly. He is somewhat passive. 


\section{Appendix D}

\section{Oral Instructions}

Hello, my name is We are conducting research on children about

things that may have happened in their lives. I would like you to talk with me and answer some questions about yourself, your family, and events you have experienced. I would also like you to fill out a questionnaire where you choose words that best describe yourself.

We are asking children/youth here at the Santa Clara County Juvenile Detention Center to participate in our study. Your participation is entirely voluntary. You do not have to participate. If there is a question you do not want to answer, you do not have to.

We will be here together for about one and half hours. Anything you tell me or write down on any of the forms will not be shown to anyone working here at the detention center or with anyone in the court system. All your answers will be listed on papers without your name on them. When we report the results of our research, your name will not be connected to any of your answers. Do you have any questions? Do you want to volunteer to participate in this study? You can stop and ask me any questions you may have at any time.

First, do you want a soft drink before we start? Now, I am going to ask you some 
questions about yourself and your life. (Read out loud, the Background Questionnaire. The interviewer will fill out the answer form.)

Next, I am going to ask you some questions about some things you might have experienced. (Read out loud Children's PTSD Inventory. Interviewer will fill out the answer form.)

Next, I want you to fill out this next part. (Read out loud the instructions section of the Emotions Profile Index.) Do you have any questions? Take as much time as you like to fill out this section.

Thank you for participating in this research study. We know how difficult it is to answer some of these questions. Sometimes it is hard for adults to answer questions about difficult life experiences and emotions. We appreciate your effort to answer the questions. Thank you again for helping us. If you feel like talking about anything we discussed today, you can ask your unit counselor to call me, or for a referral to a guidance counselor. 
Appendix E

\title{
Letter to Potential Participants
}

\section{Study of Juvenile Offenders, Life Events and Aggression}

\author{
Dear Parent/Guardian:
}

Your assistance is requested in conducting a study concerning juvenile offenders. life events and aggression. The results of the study should increase our understanding of the degree to which life events and aggression influence conduct leading to juvenile confinement. I would like to invite to participate.

(child's name)

The study will take approximately 90 minutes. It will consist of a background questionnaire on life events. a personal interview. and a two page. multiple choice questionnaire. describing personality traits.

Attached is a consent form. along with a contact number, if you have any question about the study. Participation is completely voluntary. The information in the study will be used solely for categorization purposes by those researchers directly involved in the study and will remain strictly confidential. If you agree to have this child participate in the study. please return the signed consent form. An appointment to meet with the child will be arranged with the Juvenile Detention Center.

Any subject may choose to discontinue participation at any time. Choosing whether to participate or not, as well as choosing to discontinue at any time during the study. will in no way affect this child's relations with San Jose State University or the Judicial System.

All information gathered will be strictly confidential and will not be used by anyone except those researchers directly involved in the study. Also, any information that could be identified with this child. will remain anonymous. and individual responses will not be reported in published or unpublished reports of this study.

If you have any questions about the study. please feel free to call me at (408) $924-5600$ or my thesis chairperson. Michael Alessandri. Ph.D.. at (408) 924-5611. If you have complaints about the research. you may contact Robert Cooper Ph.D.. Psychology Department Chairperson. at (408) 924-5600. Also. if you have questions or complaints about research subjects' rights, or in the event of a research-related injury. please contact Serena Stanford. Ph.D.. Associate Academic Vice President for Graduate Studies and Research. at (408) 924-2480.

Sincerely.

Nancy J. Schrack

San Jose State University - Student Researcher 
Appendix F

(San Jose State Letterhead)

\section{AGREEMENT TO PARTICIPATE IN RESEARCH \\ RESPONSIBLE INVESTIGATOR: NANCY J. SCHRACK \\ TITLE OF PROTOCOL: JUVENILE OFFENDERS, LIFE EVENTS, AND \\ AGGRESSION}

has volunteered to participate in the research study investigating the influence of life events on juvenile offender behavior and aggression. YOUTH DETAINED IN THE JUVENILE DETENTION CENTER WLL BE PARTICIPANTS IN THE STUDY. I understand that the above name youth will be given a questionnaire about events that may have occurred in their life and a second questionnaire describing personality or emotional traits that best describe the subject. The subject will participate in a personal interview about life events and their feelings about these events. The study will take place at Santa Clara County Juvenile Detention Center. I understand that all information that can be identified the youth will remain anonymous in published or unpublished reports of this study. No risks or direct benefits are anticipated from participation in this study.

Questions about the research study can be addressed to the principal investigator. Nancy Schrack $(408)$ 924-5600 or her thesis chairperson. Dr. Michael Alessandri, (408) 924-5611. Complaints about the research may be presented to the Psychology Department Chairperson. Dr. Robert Cooper. (408) 924-5600. Questions or complaints about the rights of research participants, or research-related injury may be presented to Dr. Serena Stanford. Associate Vice President of Graduate Studies and Research. at (408) $924-2480$.

The juvenile court judge's signature on this document indicate consent to participate in the study.

Child's Name Age Sex: $M$ $F$

(Print name)

Signature

Date

Juvenile Court Judge

The researcher's signature on this document indicates agreement to include the above named subject in the research and attestation that the subject has been fully informed of his or her rights.

Investigator's Signature Date

A signed copy of our agreement will be given to the juvenile court for your records. A signed copy of our agreement will be given to the above youth acting as the subject. 
Appendix G

\section{AGREEMENT TO PARTICIPATE IN RESEARCH}

\section{RESPONSIBLE INVESTIGATOR: NANCY J. SCHRACK}

\section{TITLE OF PROTOCOL: JUVENILE OFFENDERS, LIFE EVENTS, AND}

\section{AGGRESSION}

We are conducting research on children about things that may have happened in their lives. I would like you to talk with me and answer some questions about yourself. your family and events you have experienced. I would also like you to fill out a questionnaire where you choose words that best describe yourself.

We are asking children/youth here at the Santa Clara County Juvenile Detention Center to participate in our study. Your participation, is entirely voluntary. You do not have to participate. If there is a question you do not want to answer. you do not have to.

We will be here together for about one and half hours. Anything you tell me or write down on any of the forms will not be shown to anyone working here at the detention center or with anyone in the court system. All your answers will be listed on papers without your name on them. When we report the results of our research. your name will not be connected to any of your answers. Do you have any questions? Do you want to volunteer to participate in this study? You can stop and ask me any questions you may have at anytime.

I have been asked to participate in the above study. I know that this study will not affect my relationship with the courts or the Juvenile Detention Center. I volunteer to take part in this study. I can choose not to answer any question I don't want to answer. I can stop participating in this study any time I want to. My rights have been explained to me, and I agree to participate.

\section{Print Name}

Date

$\begin{array}{ll}\text { Age } & \text { Sex: } \mathbf{M} \text { S F } \\ \text { Sign Name___ }\end{array}$

The researcher's signature on this document indicates agreement to include the above named subject in the research and attestation that the subject has been fully informed of his or her rights. Investigator's Signature Date

Questions about the research study can be addressed to the principal investigator. Nancy Schrack (408) 924-5600 or her thesis chairperson. Dr. Michael Alessandri. (408) 924-5611. Complaints about the research may be presented to the Psychology Department Chairperson. Dr. Robert Cooper. (408) 924-5600. Questions or complaints about the rights of research participants, or research-related injury may be presented to Dr. Serena Stanford. Associate Vice President of Graduate Studies and Research. at (408) $924-2480$.

A signed copy of our agreement will be given to you. 
Appendix $\mathrm{H}$

SJSU Consent Letter to Use Human Subjects

\section{4 SANJOSE

TO: Nancy Schrack

520 University Ave., \#17

Los Gatos. CA 95030

FROM: $\quad$ Serena W. Stanford AAVP. Graduate studaes \& Research

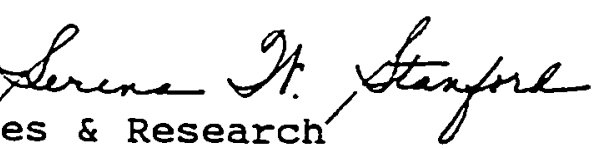

DATE:

May 7. 1996

The Human Subjects-Institutional Review Board has approved your request to use human subjects in the study entitled:

"Emotional Profiles of Juvenile offenders"

This approval is contingent upon the subjects participating in your research project being appropriately protected from risk. This includes the protection of the anonymity of the subjects' identity when they participate in your research project, and with regard to any and all data that may be collected from the subjects. The Board's approval includes continued monitoring of your research by the Board to assure that the subjects are being adequately and properly protected from such risks. If at any time a subject becomes injured or complains of injury, you must notify serena Stanford, Ph.D., immediately. Injury includes but is not limited to bodily harm, psychological trauma and release of potentially damaging personal information.

Please also be advised that all subjects need to be fully informed and aware that their participation in your research project is voluntary, and that he or she may withdraw from the project at any time. Further, a subject's participation, refusal to participate, or withdrawal will not affect any services the subject is receiving or will receive at the institution in which the research is being conducted. 
Appendix I

Court Consent to Interview Youth.

IN THE SUPERIOR COURT OE TUE STATE OE CAITEORNIA IN AND FOR THE COUNTY OF SANTA CLARA

\section{AGREEMENT TO PARTICIPATE IN RESEARCH}

TITLE OF FROTOCOL: Post-Traumatic Stress Disorder and Aggression Levels

RESEONSIBLE INVESTIGÄTOR: NancY $J$. Schrak ASSISTANT: Naomi MCDaniel

The Juvenile hall Superintendent is authorized to permit Nancy Schrak a San Jose State University Masters candidate and her assistant Naomi McDaniel to interview selected detained youth as part of a research proposal. Referred youth will participate voluntarily. Ms. Schrak and her assistant will meet existing volunteer standards and will be oriented to the security of the facility and confidentiality of information. Access to Jis is not authorized. The research proposal has been reviewed and approved by the Juvenile Hall Superintendent and the Mental Health Unit located in Juvenile hall.
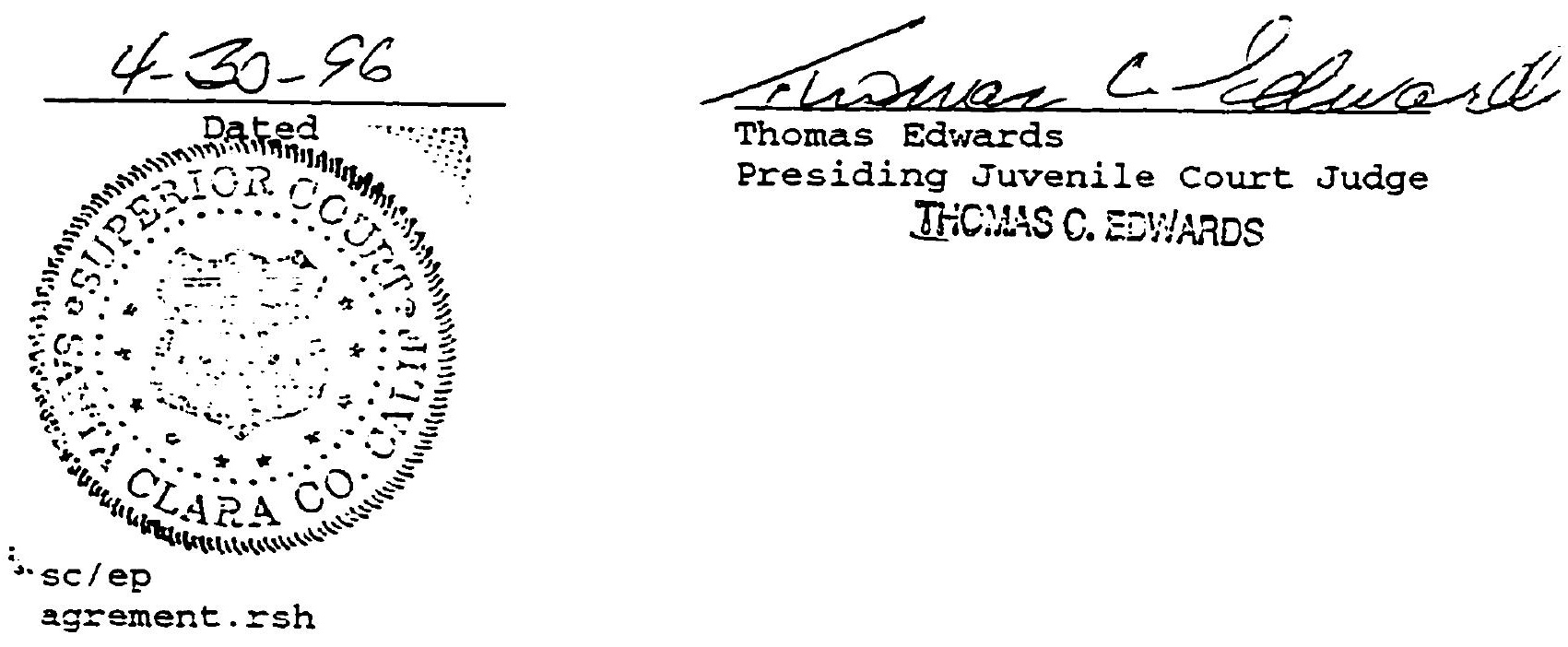


\section{Appendix $\mathrm{J}$}

Dr. Saigh Consent to use CPTSD-I.

\begin{tabular}{|c|c|c|}
\hline $\begin{array}{l}\text {-EE } \\
\text { GRAOUATE SCHOOL } \\
\text { LNO } \\
\text { UNMLRSTY CENTER }\end{array}$ & & 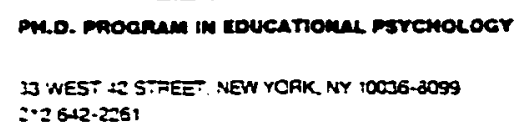 \\
\hline FE CITY LINNERSTITY OF NEW YCRK & $\cdots-\ldots$ & - \\
\hline
\end{tabular}

February 23, 1996.

Ms. Nancy Schrack

San Jose State University

520 University Avenue

Los Gatos, CA 95030-4432

Dear Ms. Schrack:

Thank you for your letter of February 21, 1996.

I am pleased to inform you that you may use the Children's PTSD Inventory as a diagnostic index.

Kindly be advised that we are in the process of calculating the reliability coefficients for the instrument as based on the responses of traumatized youth. It is anticipated that this work will be completed in April. For now, I can say that the percentage of diagnostic agreements based on a test retest procedure is very high and $\mathrm{I}$ anticipate that the kappas will also be robust.

Please feel free to contact me if I can be any assistance.

Sincerely,

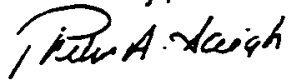

Philip A. Saigh, Ph.D.

Professor

\begin{tabular}{|c|c|c|c|}
\hline 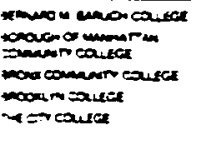 & 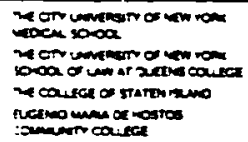 & 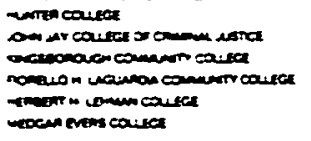 & 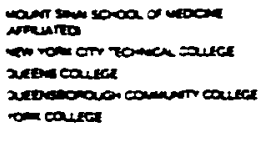 \\
\hline
\end{tabular}

